\title{
Effectiveness of interventions on the appropriate use of opioids for noncancer pain among hospital inpatients: $A$ systematic review
}

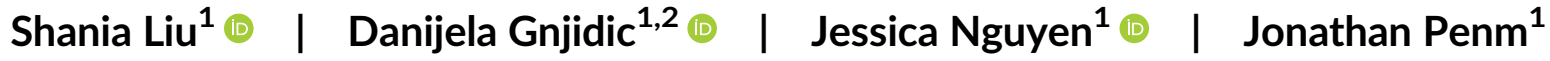

${ }^{1}$ Sydney Pharmacy School, The University of Sydney, Camperdown, NSW, Australia

${ }^{2}$ Charles Perkins Centre, The University of

Sydney, Camperdown, NSW, Australia

\section{Correspondence}

Shania Liu, A15-Pharmacy and Bank Building, The University of Sydney, Camperdown, NSW, Australia.

Email: sliu9823@uni.sydney.edu.au

Funding information

National Health and Medical Research Council (NHMRC) Dementia Leadership Fellowship;

University of Sydney
Aims: To summarise the effectiveness of interventions on appropriate opioid use for noncancer pain among hospital inpatients.

Methods: Two reviewers independently searched 6 databases up to March 2018 original research articles reporting on quantitative outcomes of interventions on appropriate opioid use among hospital inpatients. Appropriate opioid use was measured by changes in prescribing, such as the lowest effective opioid dose and duration, or clinical outcomes such as adequate pain control. Quality and intervention complexity assessments were performed by 2 independent reviewers. The full methodological approach was published on PROSPERO (ID: CRD42 019145947).

Results: Of 398 full-text articles assessed for eligibility, 37 articles were included in the review. Most articles had a moderate or high risk of bias (27 of 37 studies). Thirty-one articles primarily addressed appropriate opioid use and 6 articles targeted opioid safety as a secondary outcome. A multifaceted approach was the most common primary intervention (16 studies) and adequate pain control was the main outcome measured (14 studies). Health provider education, reinforced by hard-copy material and feedback, was associated with a 13.0 to $29.5 \%$ increase in the proportion of opioid prescriptions written in concordance with local guidelines and reduced pain scores ranging from 7.0 to $34.5 \%$. Interventions to improve opioid safety in patient-controlled analgesia reduced medication errors by up to $89.1 \%$.

Conclusion: Interventions involving academic detailing and education, especially when reinforced by feedback, show positive effects on appropriate opioid use among hospital inpatients. Future studies investigating the impact of administrative interventions on opioid use and related outcomes are warranted.

KEYWORDS

hospital, inpatients, intervention, opioid, pain management

\section{$1 \mid$ INTRODUCTION}

Opioid analgesics are commonly used to manage moderate to severe acute pain among hospital inpatients. ${ }^{1}$ The National Institute for
Health and Care Excellence identified opioids as a high-risk medicine ${ }^{2}$ as they account for up to $16.1 \%$ of hospital adverse drug events (ADEs). ${ }^{3-5}$ Opioid-related ADEs include constipation, nausea, sedation and respiratory depression. The association between opioid-related 
ADEs and adverse clinical outcomes, including increased length of hospital stay, costs, rate of readmission and even death, are well documented..$^{6-9}$

Recent attention has been placed upon optimising opioid use and reducing related harms through the development of clinical prescribing guidelines. Guidelines for the management of acute noncancer pain recommend initial nonopioid analgesia, and if insufficient, the addition of the lowest effective dose of immediate-release opioid analgesia for $<3-5$ days. ${ }^{10}$ Although the introduction of these guidelines was associated with some reduction in unnecessary opioid use, further improvements may be observed when linked with additional interventions to reinforce the implementation of these recommendations into clinical practice. ${ }^{11,12}$ Therefore, numerous systems-level interventions to promote appropriate opioid prescribing have been implemented internationally in a variety of settings. ${ }^{13,14}$

A 2017 Cochrane review investigated the effectiveness of such interventions to reduce opioid use in the outpatient setting. ${ }^{15}$ The interventions reported in the review predominantly involved adjuvant therapies, such as cognitive behavioural therapy. However, these therapies were targeted to address opioid use in the management of chronic pain in the primary care setting, which have limited evidence for treating acute pain among hospital inpatients. Moreover, the overall findings of the review were mixed. Currently, no systematic review has been conducted to investigate the effect of interventions on the appropriate use of opioids in the hospital setting. Therefore, the aim of this systematic review was to investigate the effectiveness of interventions on opioid appropriateness during inpatient admission for noncancer pain.

\section{2 | METHODS}

This review was performed in adherence to the Preferred Reporting Items for Systematic reviews and Meta-Analyses (PRIMSA) guidelines. ${ }^{16}$ The protocol for this systematic review was published on PROSPERO on 27 November 2019 (ID: CRD42019145947).

\subsection{Inclusion and exclusion criteria}

Inclusion criteria included original peer-reviewed research articles that reported quantitative outcomes of interventions on appropriate opioid use for noncancer pain during inpatient stay. A significant proportion of hospitalised patients are prescribed opioid analgesics in the emergency department (ED), ${ }^{1}$ thus interventions conducted in this setting were included in the review. Given the paucity of clinical trials available in this area, observational studies were also included to capture data relevant to this review. Appropriate use could be measured by changes in prescribing practices, such as using the lowest effective opioid dose and duration or guideline adherence, or clinical outcomes such as reduced pain intensity or length of stay (LOS). We excluded studies which exclusively reported on opioid use related to palliative care, oncology or opioid-substitution therapy as they were outside

\section{What is already known about this subject}

- Harms related to opioid analgesics among hospital inpatients are well documented.

- A range of interventions have been trialled to improve the appropriate use of opioids, however, they have yielded mixed findings.

- No review has been conducted to summarise the effect of interventions addressing opioid use in the hospital inpatient setting.

\section{What this study adds}

- We identified 37 studies using 4 main types of interventions to optimise opioid use, ranging from opioid-targeted strategies such as multifaceted interventions, decisionmaking tools, and pain-monitoring, to broader medication safety interventions.

- Interventions involving education for health care providers and patients, particularly when reinforced by performance feedback or hard-copy material, contribute towards improved prescribing and clinical outcomes related to opioid use among hospital inpatients.

the scope of this review. Studies focusing on discharge opioid use were excluded as they often included interventions in the primary care setting. We also excluded studies involving participants below the age of 18 years; case reports/series, conference abstracts, expert opinion or literature reviews; or studies written in languages other than English.

\section{2 | Search strategy}

A systematic search was conducted using 6 electronic databases. This search was applied to Medline (1960-Present) and adapted for Scopus (1960-Present), Embase (1969-Present), Cochrane Central Register of Controlled Trials (1995-Present), International Pharmaceutical Abstracts (1970-Present) and PsycINFO (1963-Present). The last search was run on 21 March 2018.

The search terms applied to all electronic databases were developed with a clinical librarian and integrated 3 key themes: opioid analgesics, by exploding the terms Analgesics, Opioid or Narcotics and listing individual opioid names; interventions that affect prescribing, by using entry term headings describing interventions in adjacency with prescribing; and the hospital inpatient setting, by exploding the entry term Hospital Departments and applying multiple field searches for inpatients, hospital and acute care. Appropriate syntax and subject headings were applied to the same key terms across all databases and the full search strategy is available in . References of relevant articles 
were also screened to identify any other potential studies not identified by the search strategy.

\section{3 | Data extraction}

After the removal of duplicates, 2 authors (S.L. and J.N.) independently screened articles by title and abstract for potentially eligible studies. Full-text articles were then assessed to confirm eligibility. Any discrepancies were brought to a third author (J.P.) for consensus to be made. We extracted author, country and year of the study conducted, study size, design and follow-up period, intervention performed, outcomes and potential sources of bias. Authors were contacted to request additional data where necessary.

\section{4 | Quality assessment}

Two authors (S.L. and J.N.) independently performed a quality assessment for all included studies using the Cochrane Risk of Bias Assessment Tool $^{17}$ for randomised controlled trials and the Risk Of Bias In Non-randomised Studies of Interventions tool ${ }^{18}$ for nonrandomised studies. Seven standard allocation criteria categorised studies as possessing low, moderate, high or unclear risk of bias for randomised controlled trials and as possessing low, moderate, serious, critical risk of bias or no information for nonrandomised studies (Appendix 2).

\section{5 | Data synthesis}

The complexity of each primary intervention was graded according to the Cochrane Intervention Complexity Assessment Tool for Systematic Reviews (iCAT_SR) ${ }^{19}$ (Appendix 3) by 2 authors (S.L. and J.N.) independently. The overall intervention complexity was calculated by assigning each criteria a score of $0-4$, indicating a low or high degree of complexity, and then averaging the total score across all of the criteria. Assessment criteria included the number of active intervention components, behaviour of recipients to which the intervention was targeted, organisational levels targeted, the degree of tailoring required to apply the intervention and the level of skill required to deliver and receive the intervention.

Studies were arranged together by: (i) interventions which addressed appropriate opioid use as a primary or secondary focus (e.g. medication safety interventions in which opioid use was a secondary outcome); (ii) the intervention type (e.g. multifaceted interventions, decision-making tools, pain monitoring). Intervention types were ordered by overall complexity using aggregated iCAT_SR scores.

Heterogeneity between studies was assessed by comparing study design, intervention approach and outcomes. Due to heterogeneity in interventions and reported outcomes between studies, a metaanalysis could not be performed.

\section{3 | RESULTS}

The search strategy generated a total of 9424 articles, of which 398 full-text articles were assessed for eligibility. Refinement using the exclusion and inclusion criteria resulted in 36 studies included in the review. One additional article was obtained by manual search of the reference list of identified articles, resulting in a total of 37 articles (Figure 1). Appropriate opioid use was addressed as the primary intervention focus in 31 articles. Six studies involved medication safety interventions and reported on changes in opioid use as a secondary outcome.

\subsection{Study characteristics}

Of the 37 articles, there were 4 randomised controlled trials (RCTs), 8 cohort studies, 23 pre-post intervention studies and 2 crosssectional studies.

Fifteen interventions involved surgical inpatients, ${ }^{20-34} 3$ were implemented in the intensive care unit, ${ }^{35-37} 7$ were conducted in the $E D,{ }^{38-44} 5$ involved geriatric inpatients ( $\geq 65$ years), ${ }^{45-49}$ and the remaining 7 studies were conducted in all inpatients, ${ }^{50-52}$ and those receiving patient-controlled analgesia $(P C A)^{53-55}$ or transdermal fentanyl. ${ }^{56}$

The interventions were performed in various countries worldwide, with the majority, 14, conducted in the USA (Tables 14). ${ }^{20-23,25,29,31,40,41,50,52,54-56}$ Due to variability in study type and interventions employed, we summarised the review according to intervention type.

\section{2 | Quality assessment}

Risk of bias assessment was performed for 4 RCTs and 33 nonrandomised studies (). Out of the 31 articles in which opioid use was evaluated as a primary outcome, 24 studies were graded as having either a moderate or serious risk of bias, largely due to confounding or selection of participants into the study. ${ }^{21-24,26-28,30-32,35-37,39-44,50,52,54-56}$ A moderate or serious risk of bias was found in 3 of 6 studies in which opioid use was addressed as a secondary outcome. ${ }^{33,34,48}$ Selective reporting of outcomes and other risk of bias were unclear in most studies. Due to a significant degree of heterogeneity between intervention approach and outcome measures, a meta-analysis was not deemed suitable.

\section{3 | Interventions primarily targeting appropriate opioid use}

Thirty-one studies examined the effect of interventions to improve prescribing or clinical outcomes related to opioid use. Interventions used to improve appropriate opioid use for analgesia included 16 articles which employed a multifaceted intervention to educate health 
FIGURE 1 Study inclusion and exclusion criteria flow diagram

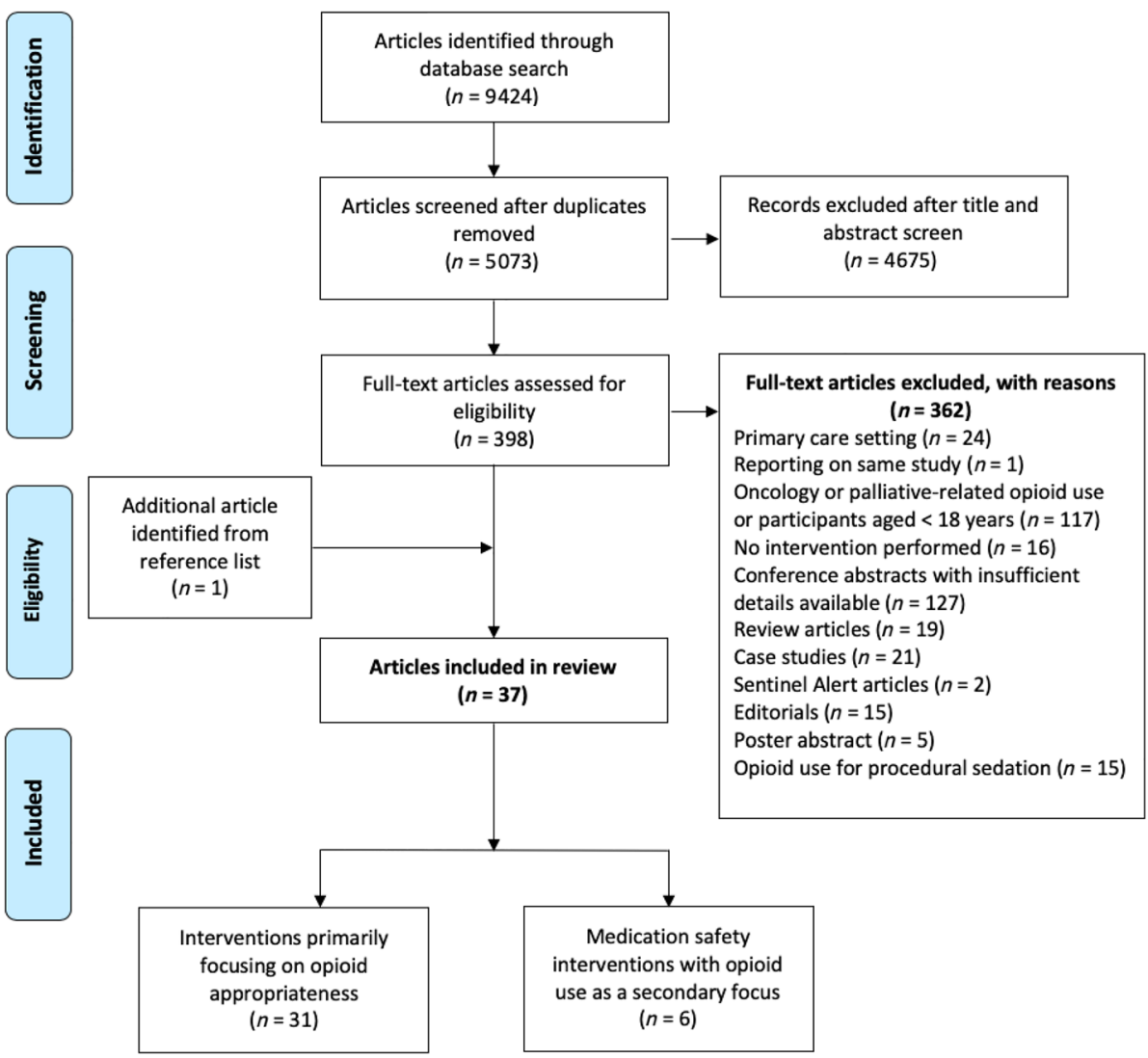

providers (such as prescribers, nurses, pharmacists) and patients to change opioid use, ${ }^{20-30,35,38,50-52} 5$ studies using decision-making tools to guide opioid prescribing ${ }^{39-42,56}$ and 10 that targeted pain monitoring and response to analgesic treatment. ${ }^{31,32,36,37,43-45,53-55}$ Predominant prescribing outcomes included the quantity of opioids prescribed and compliance to published guidelines, while clinical outcomes included pain intensity, opioid-related ADEs and patient satisfaction with adequate pain control. To some extent, greater intervention complexity was associated with effectiveness on improving patterns of opioid use ().

\subsection{1 | Multifaceted interventions primarily aimed at prescribing}

Sixteen studies examined the effect of multifaceted interventions involving education to change patterns of opioid use. ${ }^{20-30,35,38,50-52}$ Of these, 8 interventions focused on educating health professionals to improve pain control, primarily through the increased use of opioid analgesia. ${ }^{20-22,35,38,50-52}$ An RCT conducted by Taylor et al. employed an educational intervention for health care professionals (doctors and nurses) and patients to achieve adequate analgesia, defined by a reduction in numerical rating scores (NRS; range 0-10) of at least 2 points and to a target score of $<4$, clinically representative of mild pain. The use of both nonopioid and opioid analgesics was supported to achieve satisfactory pain control. Education was reinforced by physical and electronic dissemination of material and daily audit and feedback provided by site investigators. Patient education was also provided to facilitate communication of the patient's concerns in pain management. While no significant changes in analgesic use were observed in the intervention group, an $11.0 \%$ increase in patient education was associated with patient improved satisfaction with pain control (42.9-53.9\%; $P=.001) .{ }^{38}$ Interventions involving health professional education reinforced by hard-copy material to improve pain control were used in 7 studies, ${ }^{21,22,35,38,50-52}$ although the definition of prescription appropriateness varied between studies. A study by Bingle et al. (1991), conducted in the context of addressing inadequate analgesia, used academic detailing (1-on-1 face-to-face educational outreach) to encourage the prescription of pethidine (meperidine) above a defined dose and frequency. ${ }^{21}$ In contrast, in a 2003 study funded by Abbot Pharmaceuticals, Boothby et al. implemented academic detailing to discourage the use of pethidine in favour of other analgesics with superior safety-efficacy profiles. ${ }^{50}$ Nevertheless, the use of academic detailing was associated with reduced prescription error rates $(41.0 \% \text { vs } 24.0 \% \text {; } P<.05)^{51}$ and increased compliance of prescribed opioids to predetermined recommendations. ${ }^{21,50}$ The provision of patient education to aid shared healthcare decision-making was associated with a significant reduction in LOS from 5.9 to 5.1 days $(P<.05)$, despite no changes in morphine use or pain intensity. ${ }^{22}$ Prescriber education through case scenario discussion alone, without further feedback, was not associated with changes in pain intensity or opioid use. ${ }^{52}$

Eight interventions involved health professional education to manage pain by encouraging the use of nonpharmacological measures 

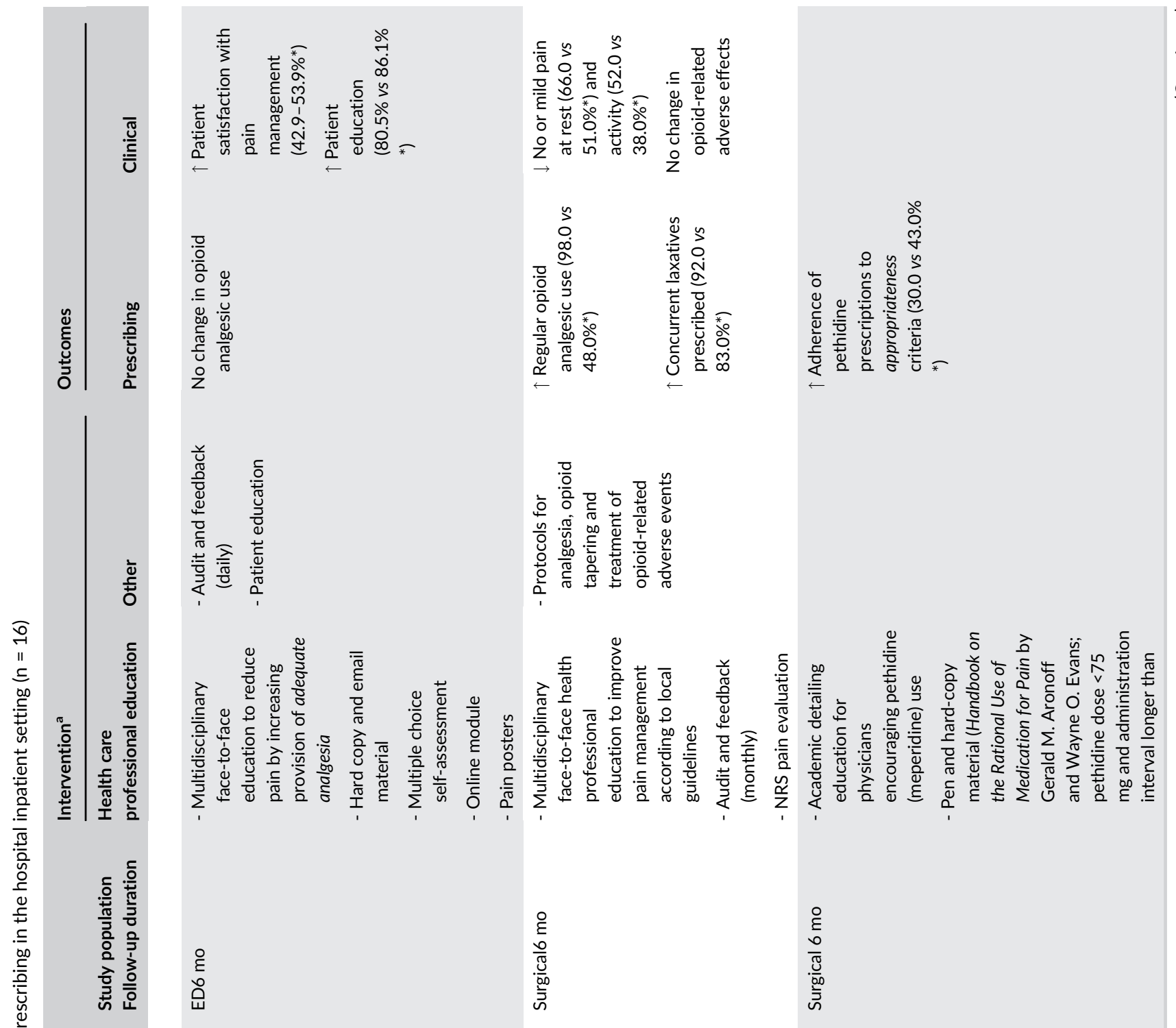

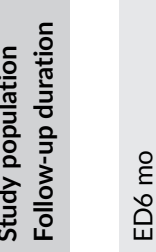
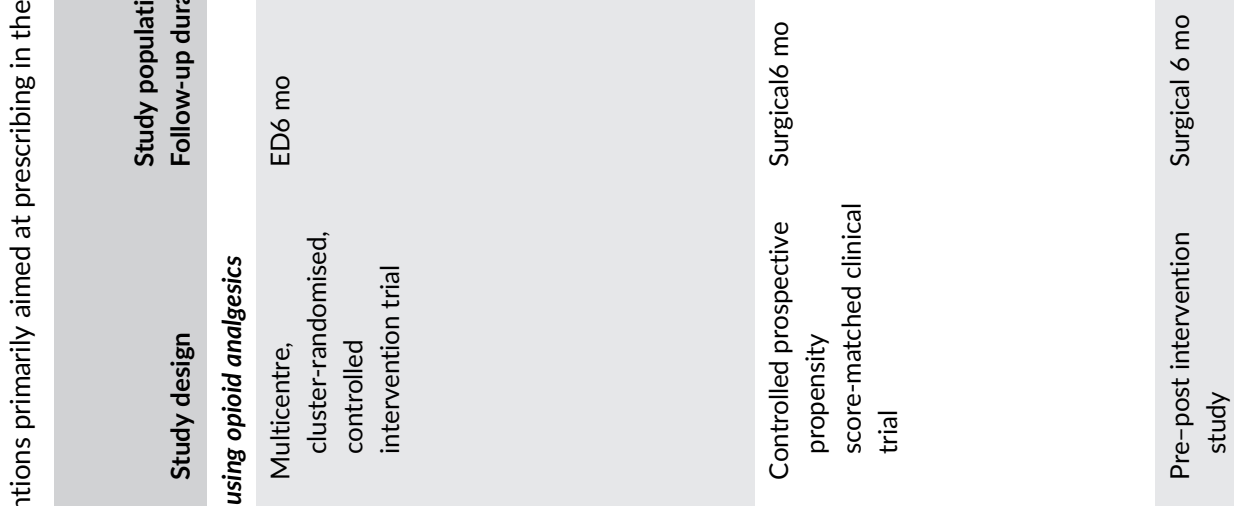

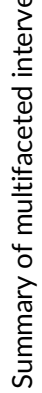

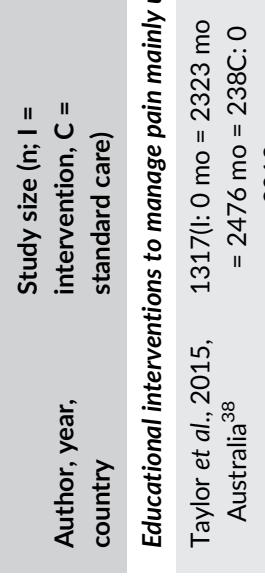

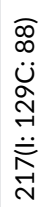

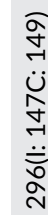

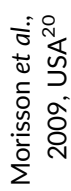

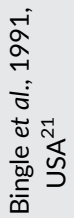




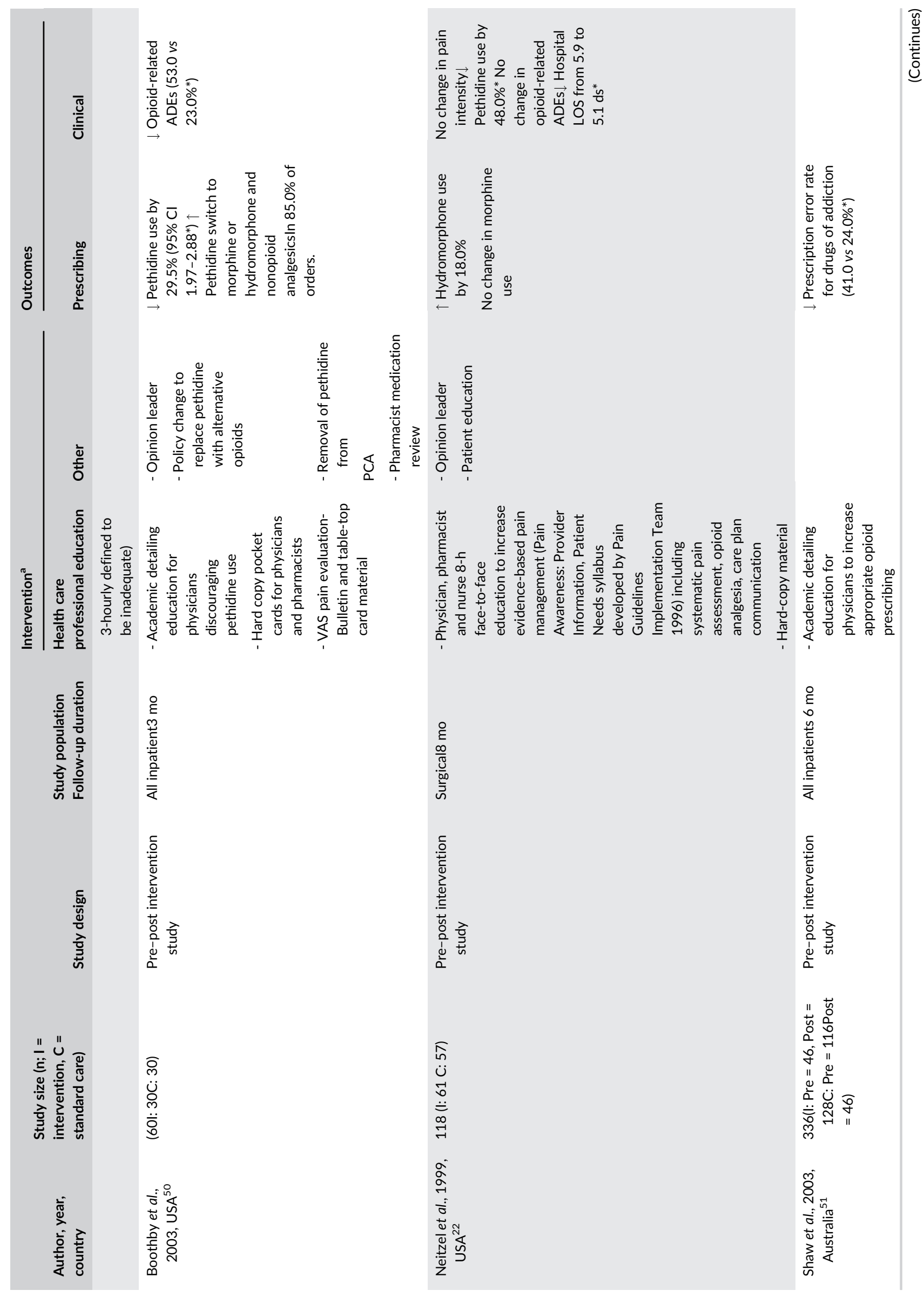



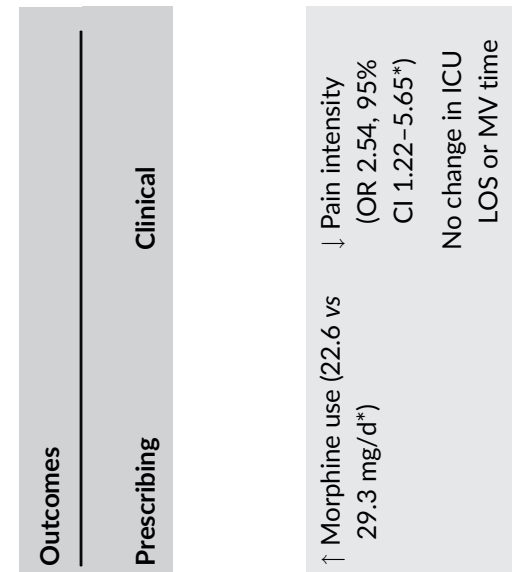

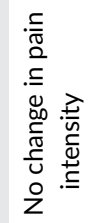

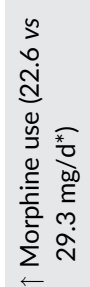

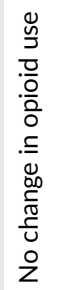

붕

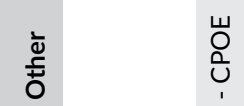

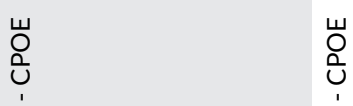

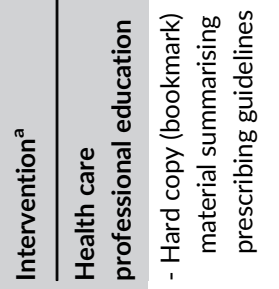
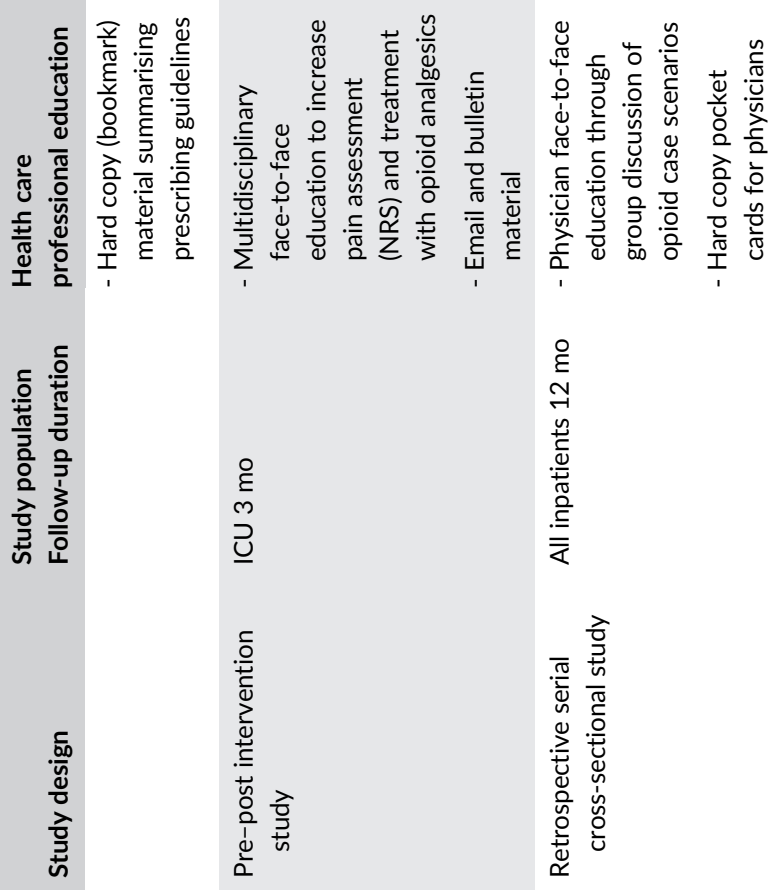

$\bar{g}$
$\underline{\underline{u}}$
产
$\underline{0}$
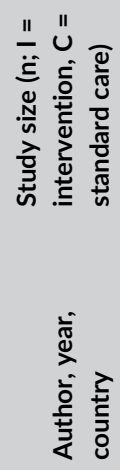

$\stackrel{ }{\varepsilon}$
$\stackrel{m}{\supset}$
$\underline{U}$

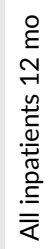

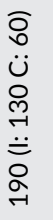

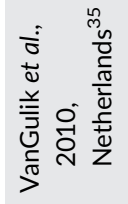

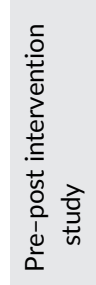

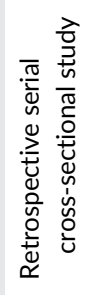

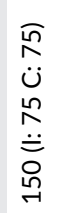

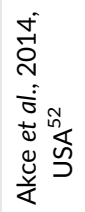

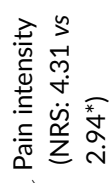

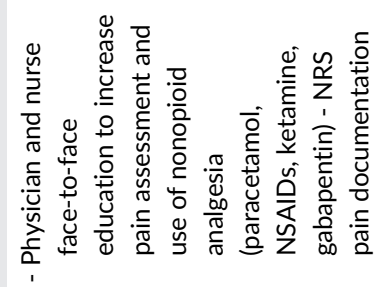

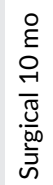

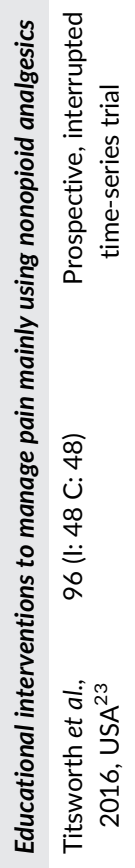

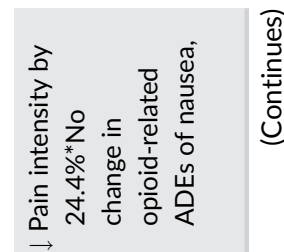

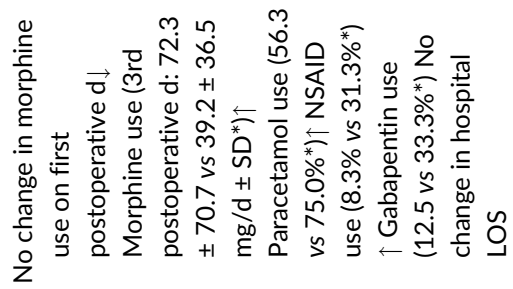
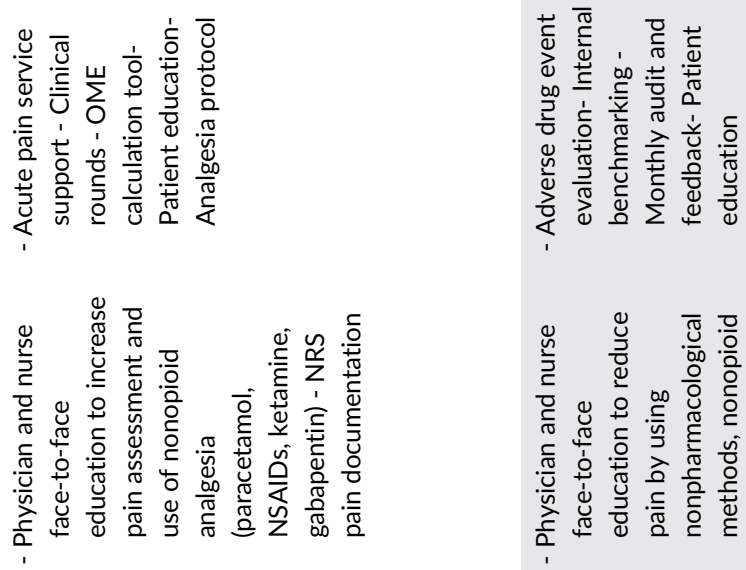

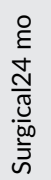

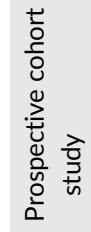

ڤ్

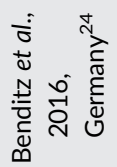




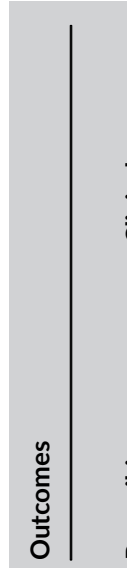

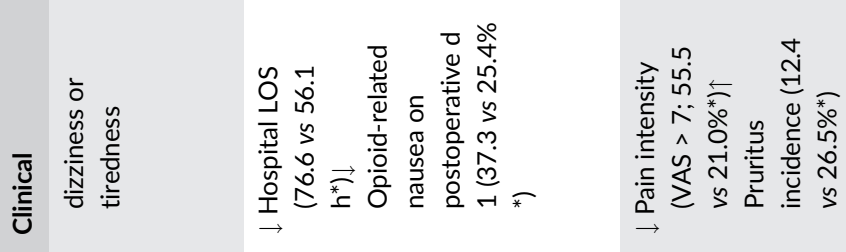

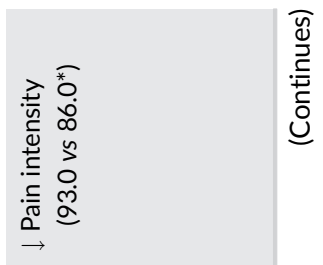

ปั
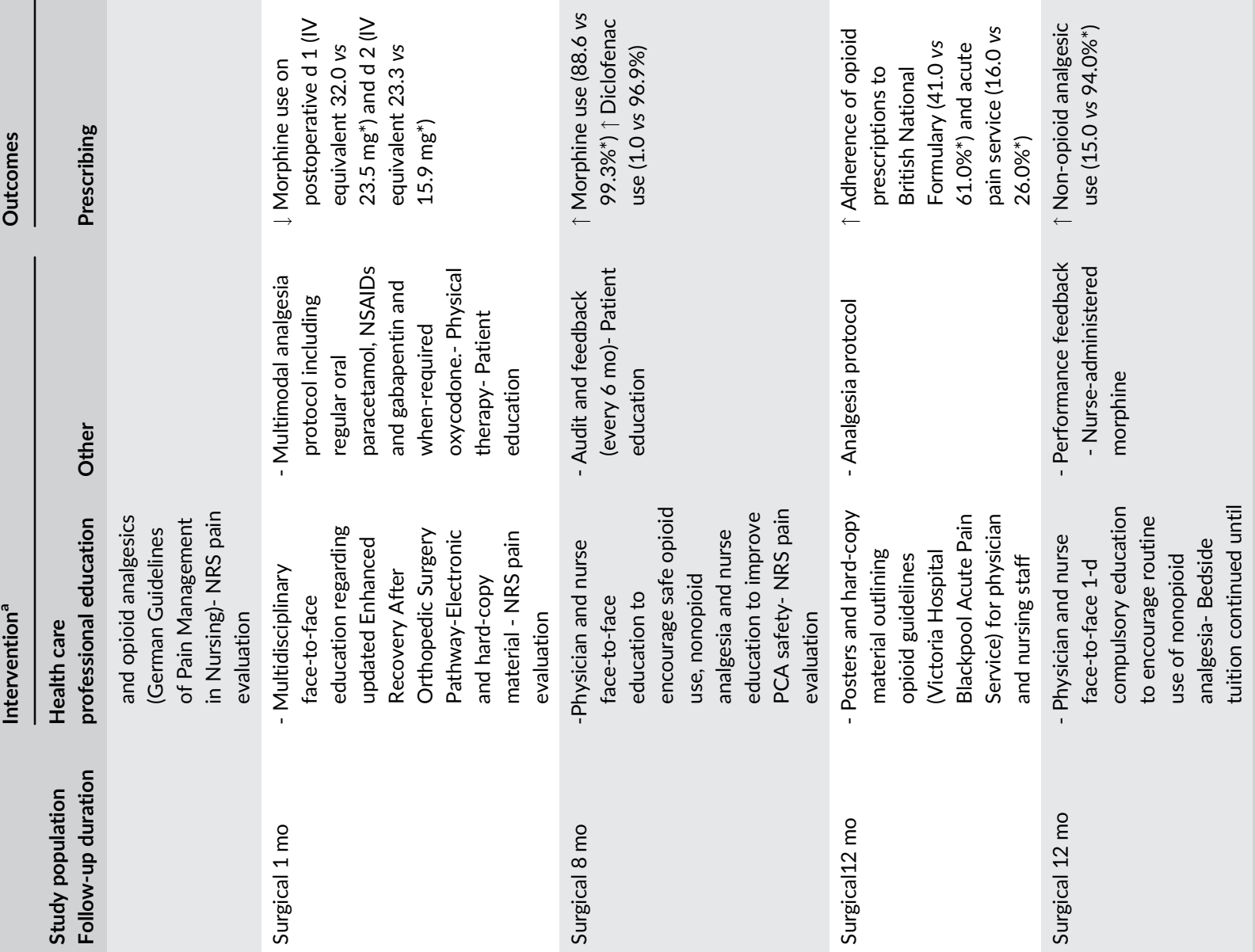

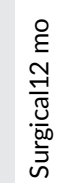

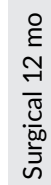

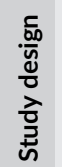
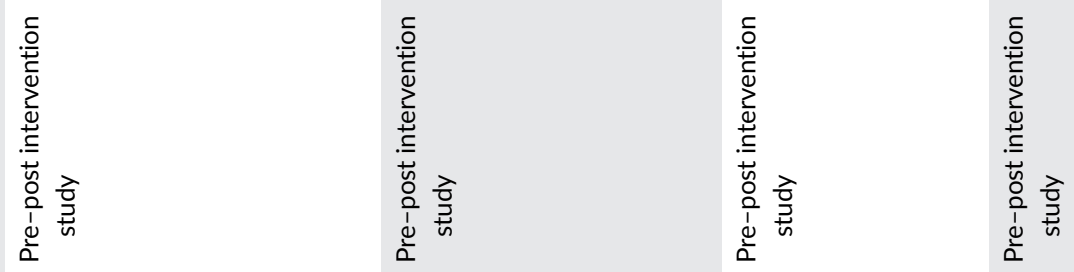

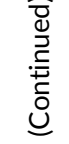

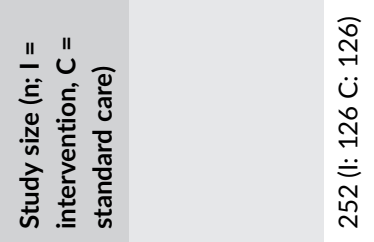

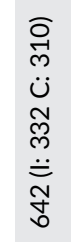

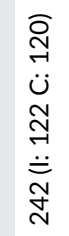

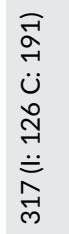
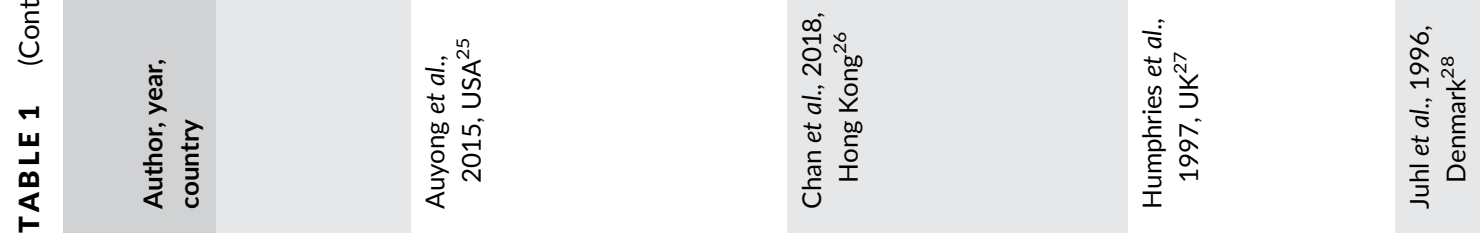


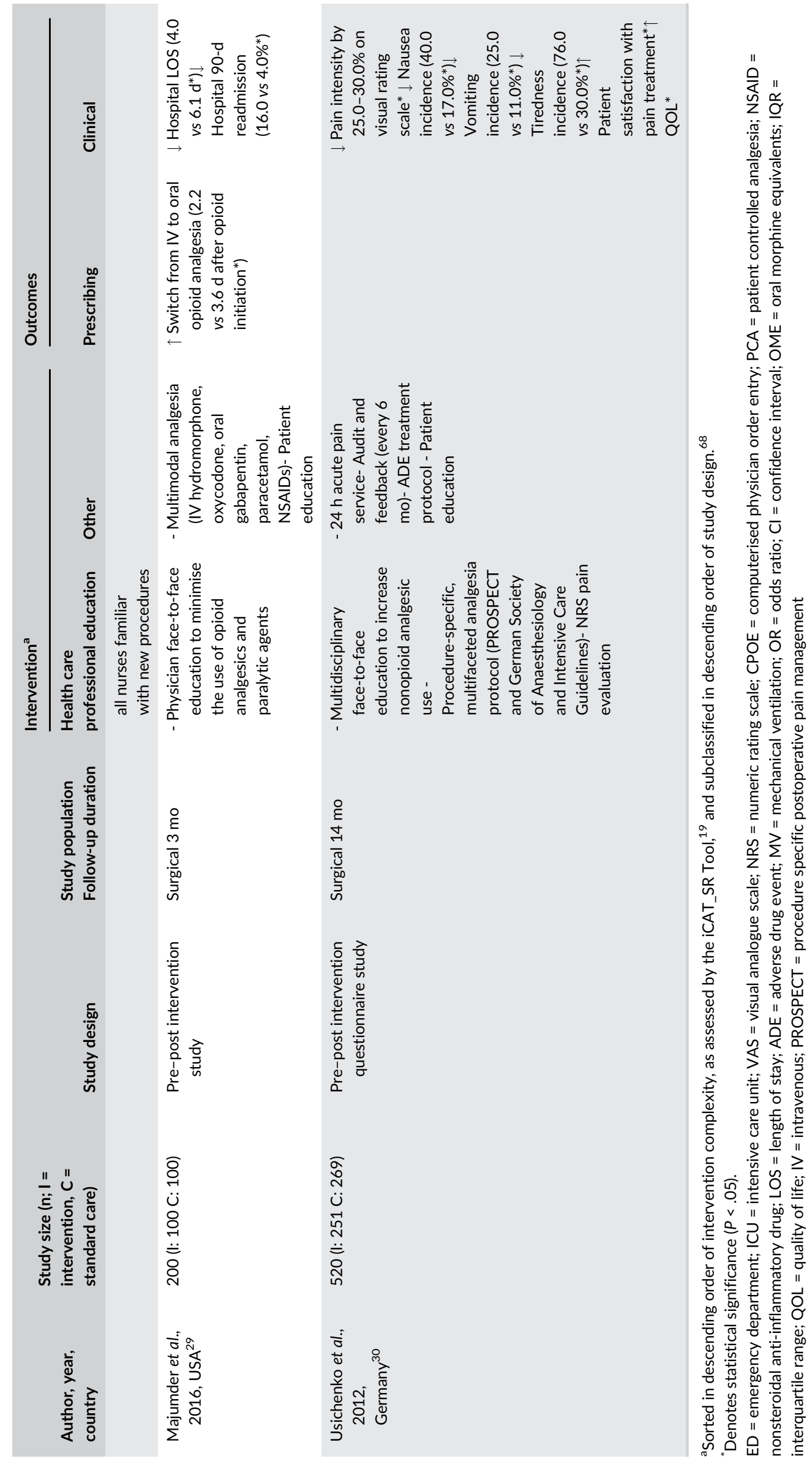



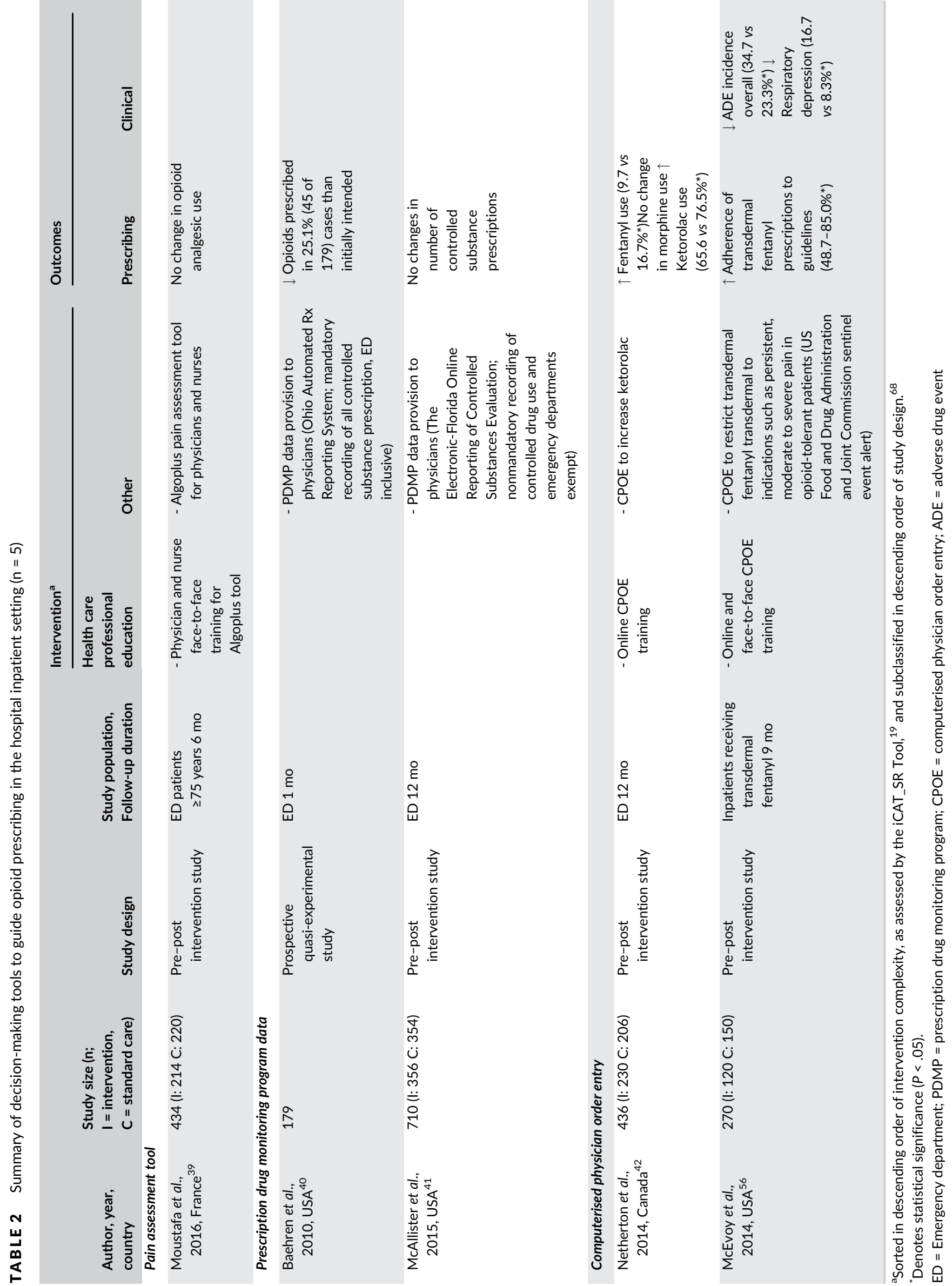


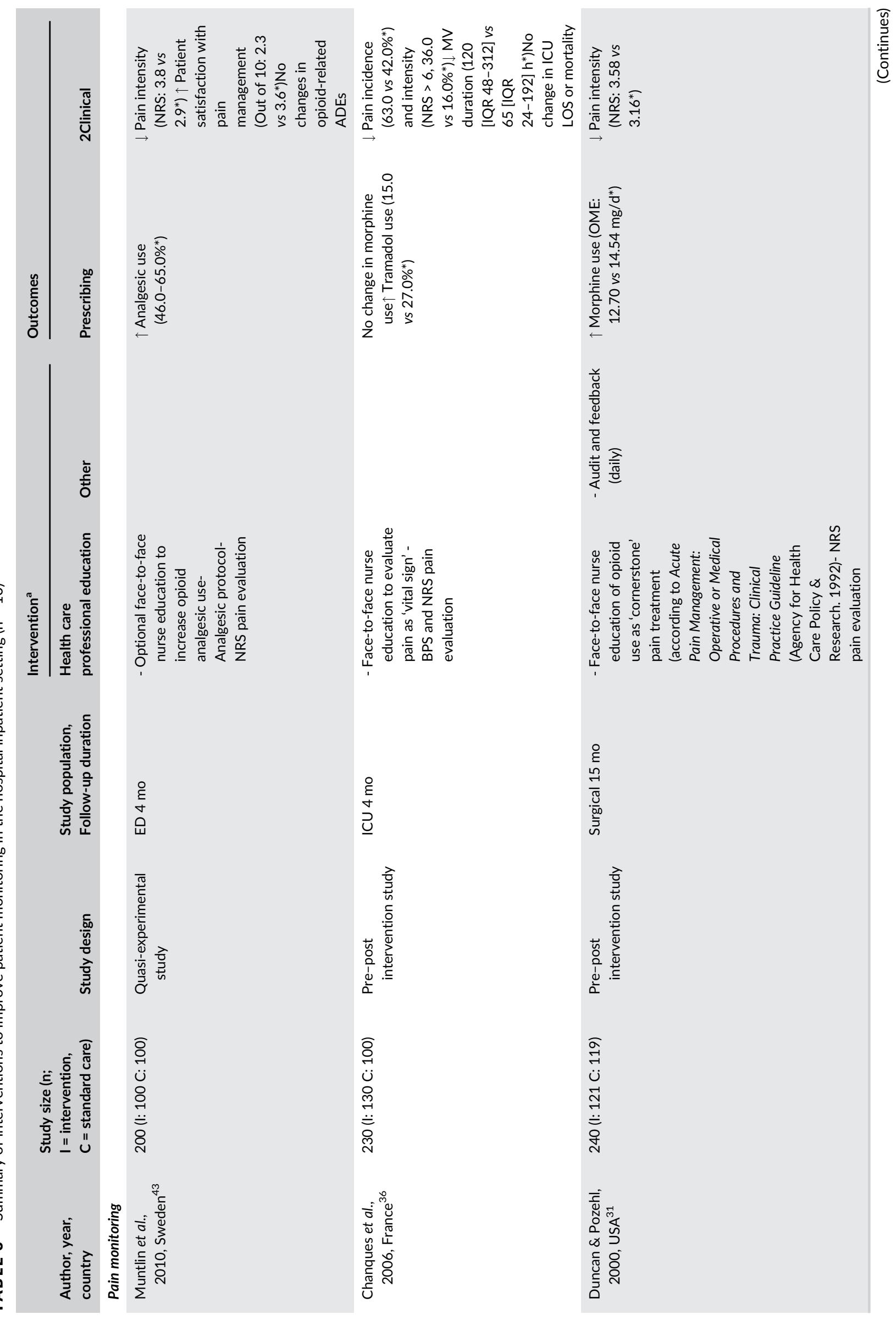




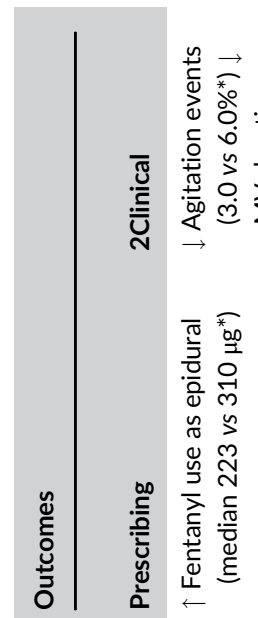

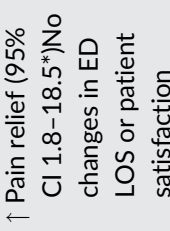

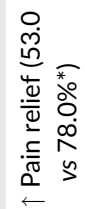

$\bar{\Phi}$
$\underline{\underline{\underline{E}}}$
产
$\underline{0}$
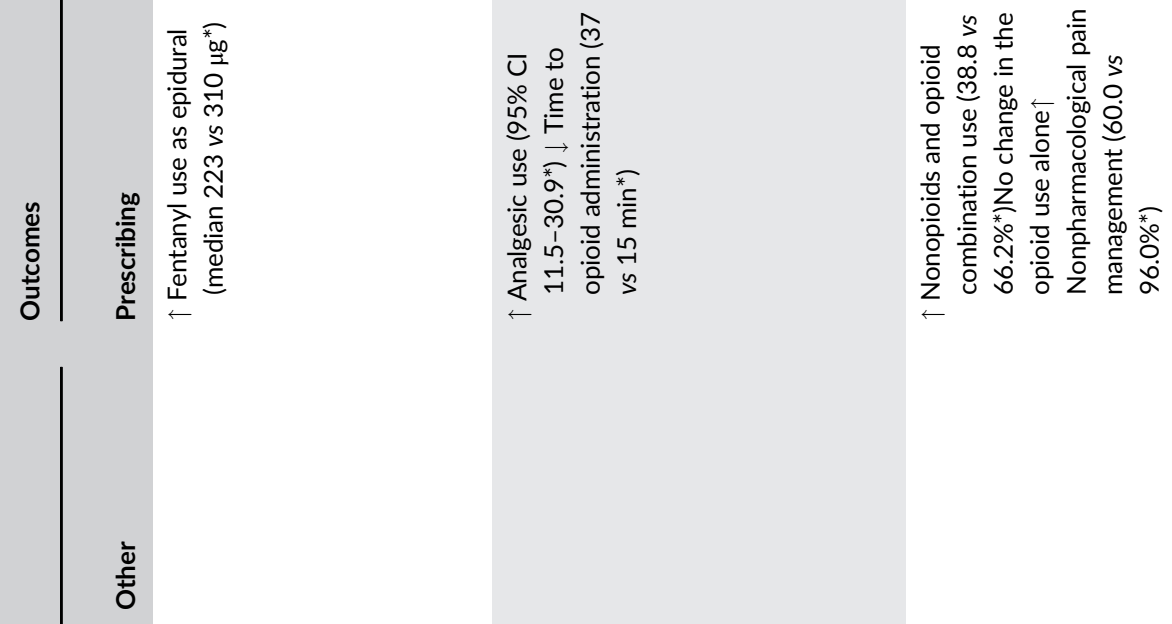

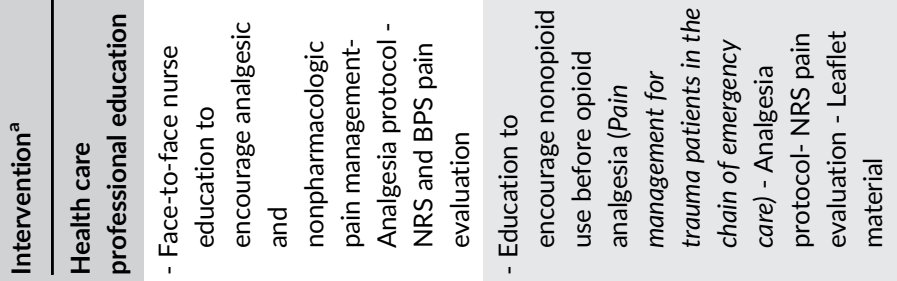
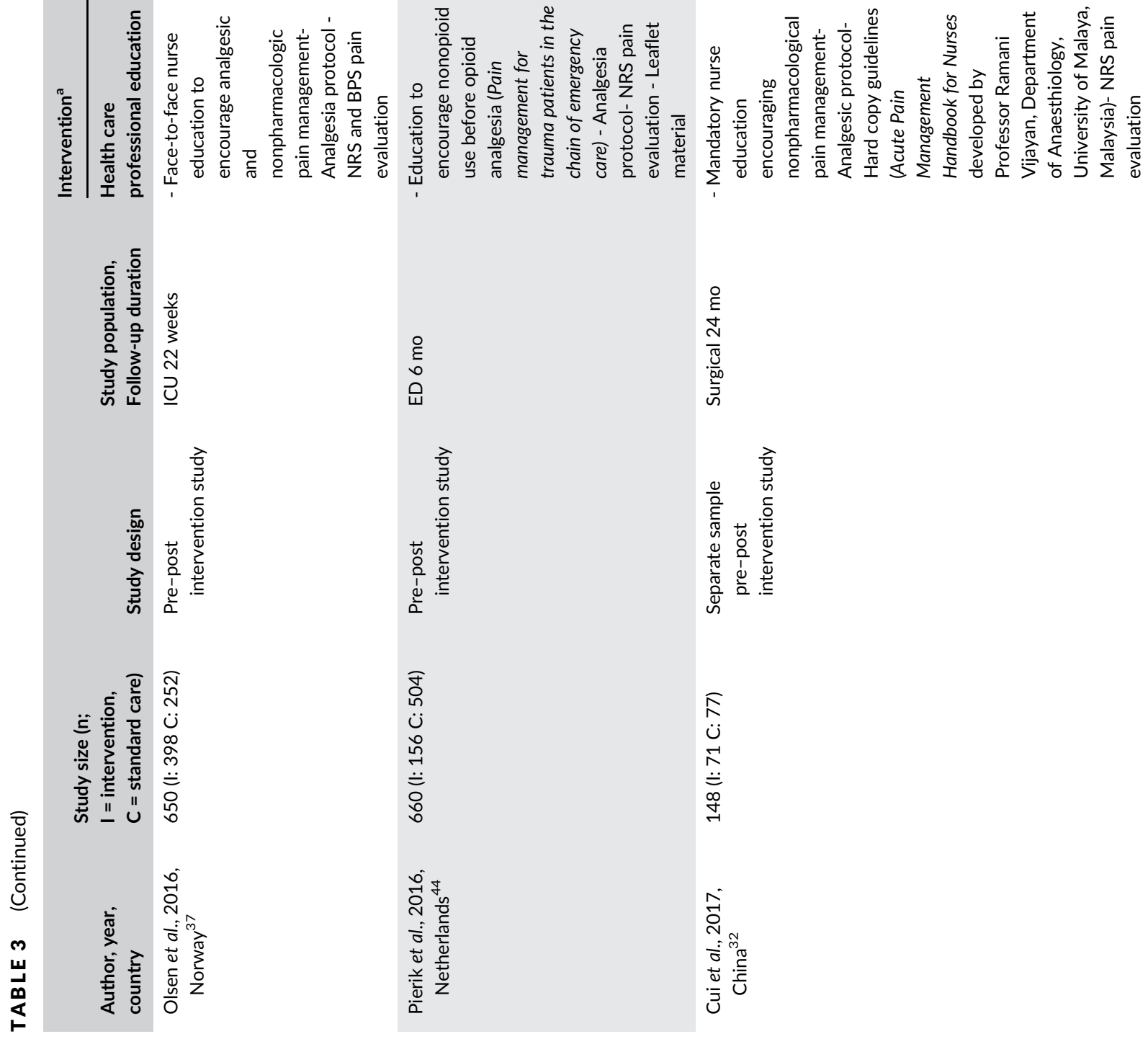


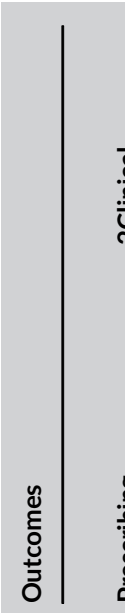

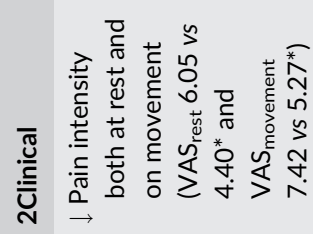
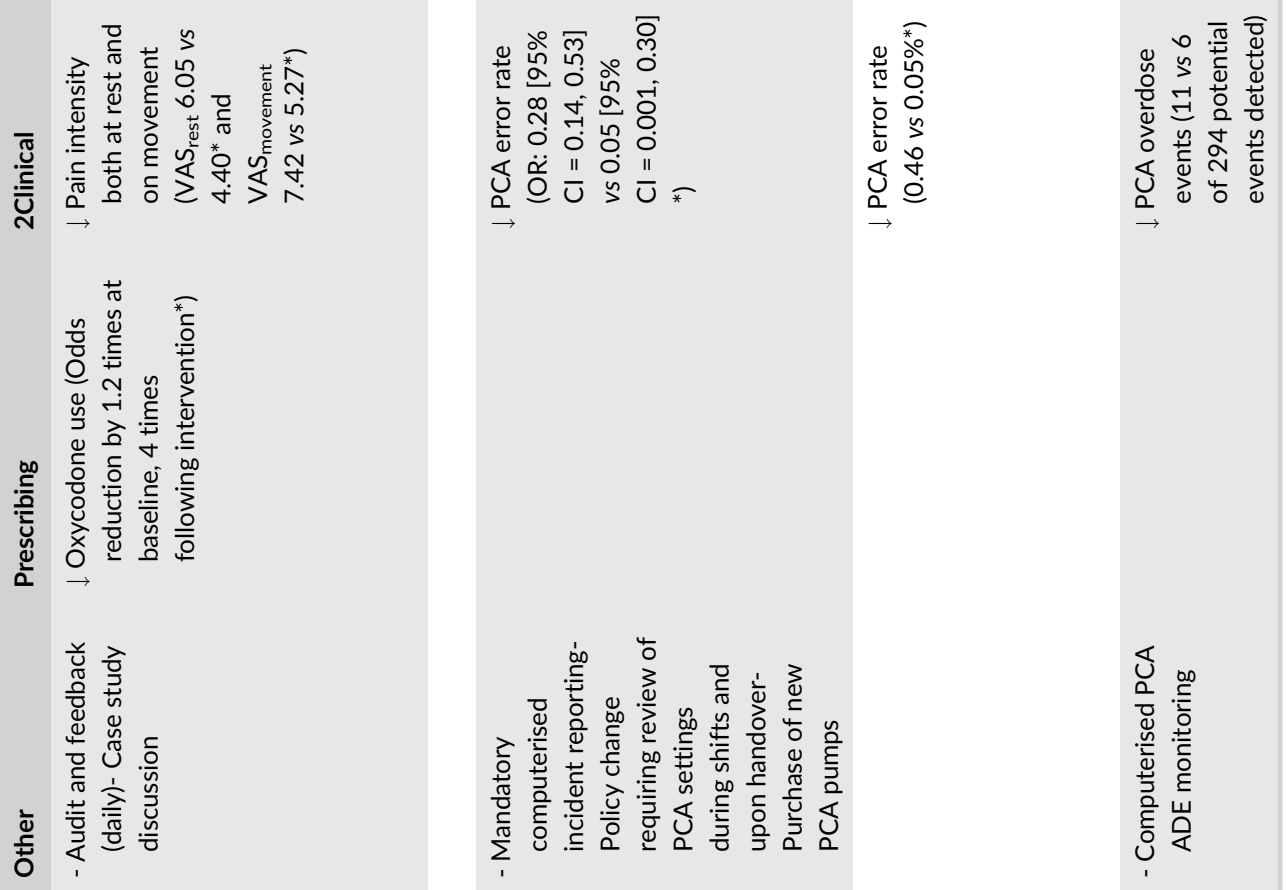

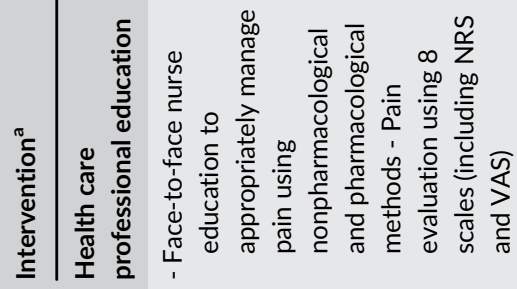
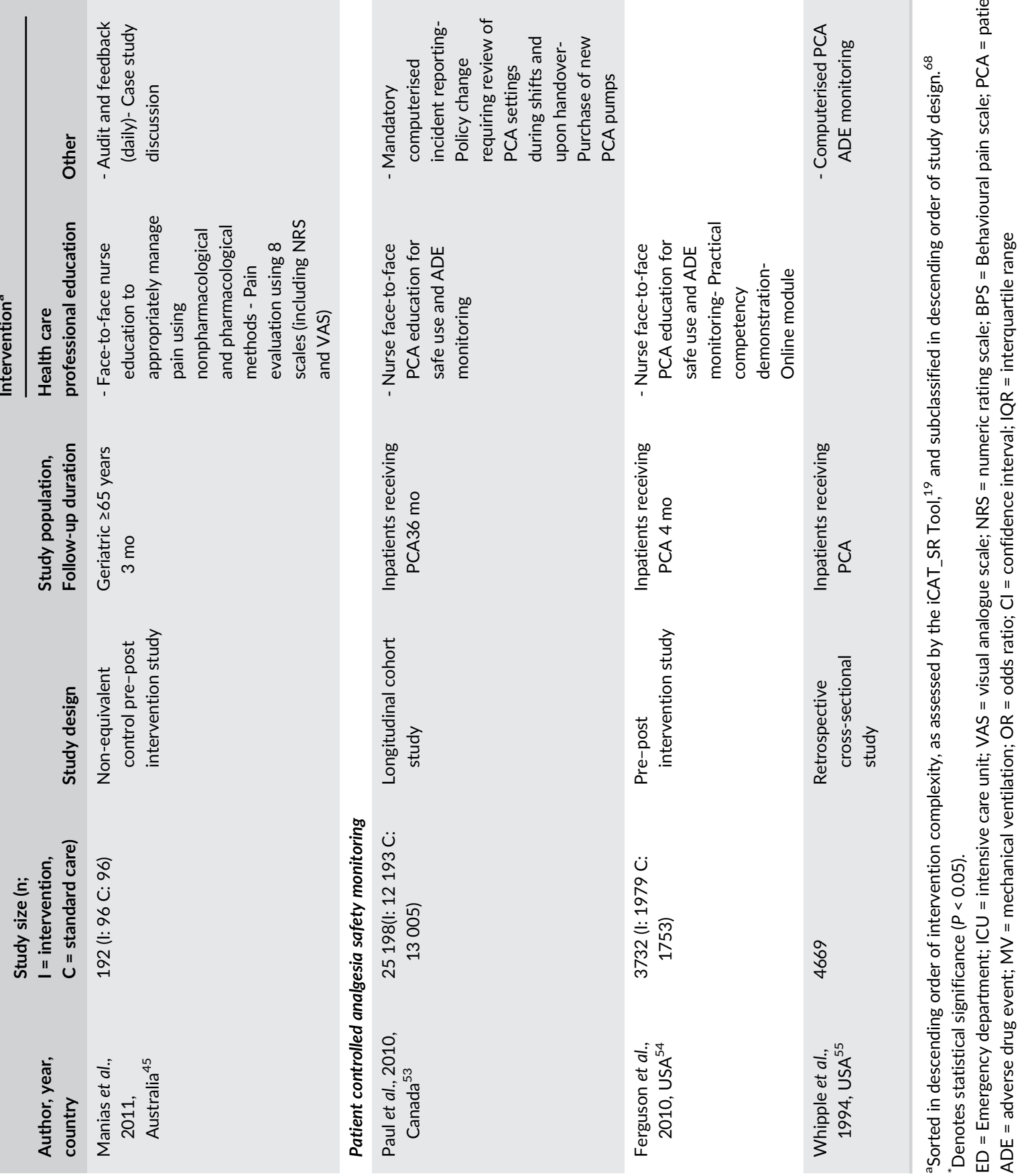


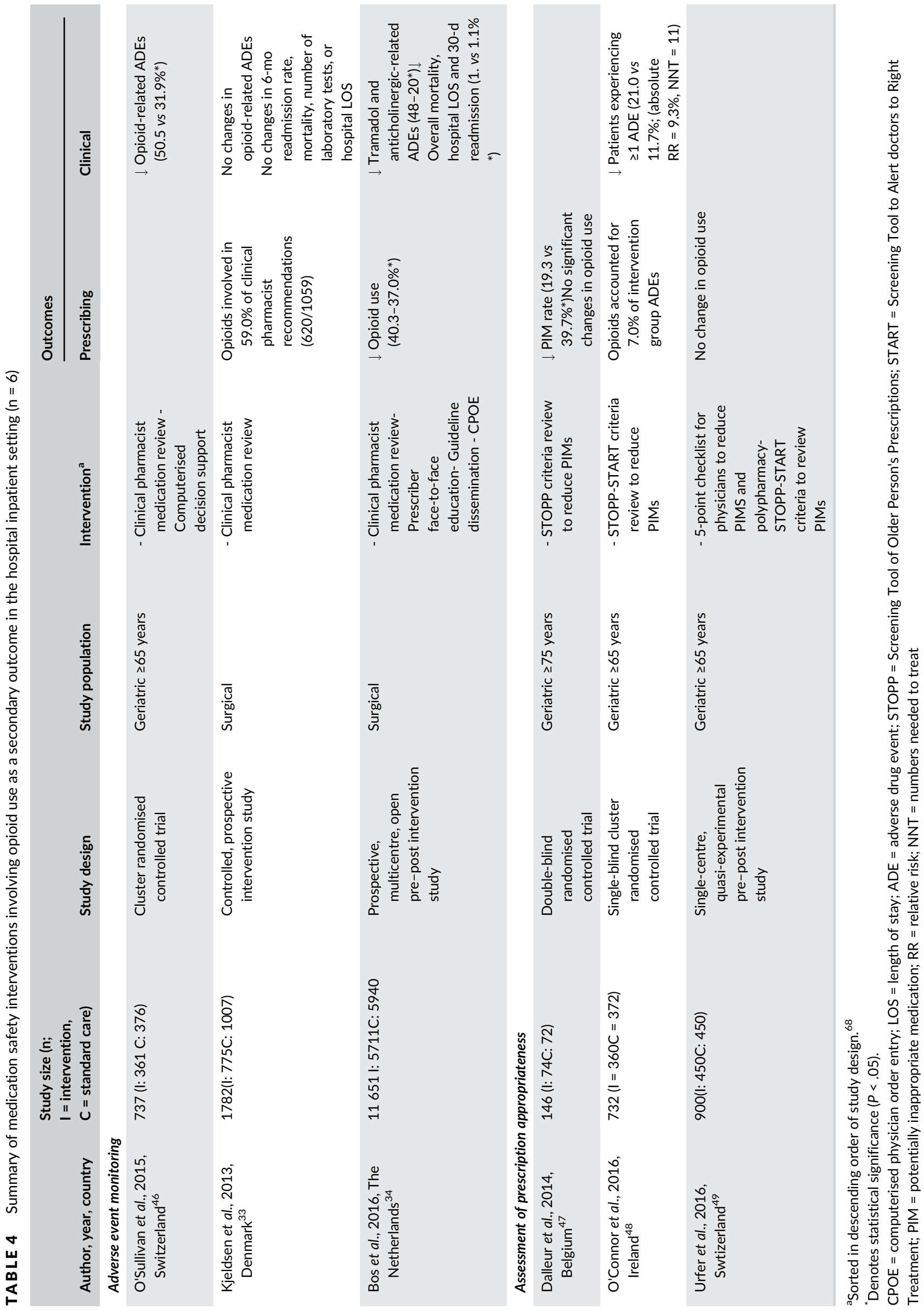


and nonopioid analgesics, reserving opioid analgesia for stronger pain. ${ }^{23-30}$ While these studies shared key education messages and mainly targeted physicians and nurses, distinctions existed between the types of additional strategies used, such as reinforcement with audit and feedback, or patient involvement in decision-making. The use of performance feedback conducted every 1-6 months to reinforce health professional education was associated with significant improvements in the primary outcome of all the studies in which it was applied, including patient satisfaction and reduced pain intensity. ${ }^{24,26,28,30}$ Additionally, 2 studies using performance feedback reported 79.0-95.9\% increased nonopioid analgesic use $\mathrm{e}^{26,28}$ and 1 study showed a reduction in opioid-related ADEs such as nausea (40.0 vs $17.0 \%$; $P<.05) .{ }^{30}$ Of 3 studies using an analgesia protocol to guide pain treatment, ${ }^{23,25,27} 1$ study demonstrated significantly increased use of nonopioid analgesia ${ }^{23}$ and 2 studies reported reduced morphine use ranging from 26.6 to $45.8 \% .^{23,25}$ Patient education was linked to significant improvements in patient satisfaction and quality of life. ${ }^{30}$

\subsection{2 | Decision-making tools to guide opioid prescribing}

Five studies used tools to guide the appropriate prescribing of opioids. ${ }^{39-42,56}$ A pain assessment tool was used in 1 study, which did not report a significant difference in the quantity of opioids used. ${ }^{39}$

Two studies, which assessed whether the provision of prescription drug monitoring programme (PDMP) data influenced prescribers' decisions about the risk of opioid misuse and subsequent analgesic prescription, produced mixed results. ${ }^{40,41}$ The study conducted by Baehren et al., in which PDMP reporting for outpatient and ED prescriptions was mandatory, reported a $25.0 \%$ reduction in opioids prescribed, ${ }^{40}$ whereas nonmandatory PDMP use from which the ED was exempt was not associated with significant differences in the prescription of controlled substances. ${ }^{41}$

Two studies used computerised physician order entry to guide prescribing. Both interventions provided online training for prescribers and showed significantly increased compliance of prescribed opioids to regulatory statements such as the Joint Commission Sentinel Event Alert on safe opioid use. ${ }^{42,56}$ In addition to online education, 1 study also used face-to-face training to support computerised order entry and reported a reduction in overall ADEs (34.7 vs $23.3 \%, P=.043$ ) and respiratory depression ( 16.7 vs $8.3 \%, P=.043) .{ }^{56}$

\subsection{3 | Patient monitoring}

Ten studies assessed the impact of increased patient monitoring on analgesic use, pain intensity and PCA-related ADEs. ${ }^{31,32,36,37,43-45,53-55}$ Seven studies assessed pain intensity by implementing scales such as the numeric rating scale and visual analogue scale. ${ }^{31,32,36,37,43-45}$ All interventions were performed primarily by nurses. Of these, 3 interventions focused on pain evaluation as a vital sign and treatment using opioid analgesics. ${ }^{31,36,43}$ These studies reported significantly increased use of morphine by $12.7 \%(P<.05)^{28}$ and tramadol by $12.0 \%(P<.05),{ }^{31}$ as well as reduced pain intensity; however, no changes in opioid-related ADEs or LOS were shown. In contrast, 4 studies used pain scales to assess pain severity and provide treatment using multimodal strategies including nonpharmacological and nonopioid methods. ${ }^{32,37,44,45}$ The use of opioid analgesics varied in these studies, however, significantly increased use of nonpharmacological pain management $(60.0$ vs $96.0 \%$; $P<0.05)$ and nonopioid analgesia (38.8 vs 66.2\%; $P<0.05$ ) were reported. ${ }^{32}$ These changes were associated with improved clinical outcomes including reduced pain intensity ranging from 27.2 to $38.5 \%,{ }^{32,45}$ reduced duration of mechanical ventilation (median 46 vs $79 \mathrm{~h} ; \mathrm{P}<.06$ ), and a nonsignificant reduction in LOS. ${ }^{37}$

Three studies evaluated the impact of increased ADE monitoring to improve PCA safety. ${ }^{53-55}$ Interventions to increase nursing assessment of patients' response to PCA and competency demonstration were introduced in 2 studies, both of which demonstrated relative reductions of $82.1-89.1 \%$ in the frequency of PCA errors. ${ }^{53,54}$ In the remaining study, a computer-based system to monitor PCA errors reported 11 of 294 potential overdose events compared to 6 detected through standard practice. ${ }^{55}$

\subsection{Medication safety intervention studies}

Six studies involved medication safety interventions, in which opioid use was addressed as a secondary focus. ${ }^{33,34,46-49}$ Of these, 3 studies examined the effects of ADE monitoring ${ }^{33,34,46}$ and 3 used specific criteria to assess prescription appropriateness. ${ }^{47-49}$

Clinical pharmacist review of medications was used in all 3 studies which monitored for ADEs. ${ }^{33,34,46}$ Medication review alone was not associated with changes in opioid ADEs. ${ }^{33}$ However, 2 studies which included additional interventions such as computerised physician order entry and dissemination of drug safety guidelines reported significant reductions in opioid use $(40.3-37.0 \% ; P<.05)$ and opioidrelated ADEs by $18.6-28.0 \% .^{34,46}$

Three studies implemented the Screening Tool of Older Person's Prescriptions and Screening Tool to Alert doctors to Right Treatment (STOPP/START) criteria to evaluate the prevalence of potentially inappropriate prescriptions compared to usual care. ${ }^{47-49}$ One RCT using STOPP/START criteria reported reduced rates of inappropriate prescriptions by $20.4 \%$ (39.7 vs $19.3 \% ; P<.05) .{ }^{47}$ However, the use these of criteria did not change opioid use. ${ }^{47-49}$

\section{4 | DISCUSSION}

\section{1 $\quad$ Principal findings}

To our knowledge, this is the first systematic review to evaluate the effectiveness of interventions on appropriate opioid use in the hospital inpatient setting. Multifaceted interventions involving academic 
detailing and education, particularly when reinforced by audit and feedback and hard-copy material demonstrated improvements on the appropriate use of opioids, which contributed towards improved clinical outcomes. Patient education was linked to increased patient satisfaction and quality of life. Pain monitoring to determine appropriate treatment was associated with the increased use of nonopioid analgesia and reduced opioid-related ADEs, while still maintaining adequate pain control. Increased concordance of opioid prescribing to published guidelines was reported after the introduction of computerised physician order entry systems. To some extent, increased intervention complexity was associated with increased effectiveness on improving appropriate opioid use. Opioid safety interventions integrating multiple strategies, such as clinical pharmacist review, computerised physician order entry and dissemination of published guidelines, facilitated greater improvements in prescribing and clinical outcomes compared to a single-component approach. However, due to the high risk of bias in many of these studies, these results require further investigation.

\subsection{Comparison with other studies}

No other review has been conducted that systematically evaluates the effectiveness of interventions on appropriate opioid use in the hospital inpatient setting. Although there is a Cochrane review (2017) that evaluates the effectiveness of interventions to reduce opioid use in the management of chronic pain, its included studies were all conducted in the primary care setting. ${ }^{15}$ The majority of the interventions included in the Cochrane review involved adjuvant therapies such as acupuncture and cognitive behavioural therapy. These interventions may also be useful in the hospital setting; however, the evidence supporting their use for acute pain is limited. Few studies implemented adjuvant therapies in this review. Further research on the impact of nonpharmacological pain management on opioid use in the hospital setting is required.

\subsection{Strengths and limitations}

The main strength of this review was the rigorous approach taken in its systematic search. Two independent reviewers determined each study's eligibility and performed quality and complexity assessments. A broad search strategy was developed with a clinical librarian and applied to 6 databases to capture an extensive amount of the available literature. Also, this search was not limited by publication year, which allowed shifts in the clinical focus of opioid use to be captured over time.

However, this review had several limitations. Firstly, a metaanalysis could not be performed due to substantial heterogeneity in intervention approach and outcomes (e.g. LOS), limiting the generalisability of our results. Moreover, the majority of studies in the present review involved follow-up periods under 24 months, therefore the long-term sustainability of these interventions is unknown.
Finally, some relevant studies may have been omitted. Although we employed a comprehensive search strategy and manually searched reference lists to include all relevant studies, only articles from the designated databases published in English were included. We did not search grey literature, thus introducing a level of publication bias.

\subsection{Policy and research implications}

Our findings highlight that the majority of studies were performed in the context of managing patients' pain through the provision of opioid analgesia, whereas fewer addressed patient safety and opioid-related harm. Interventions aimed at increasing the use of opioids reflect recommendations by the American Pain Society in 1995 to evaluate pain as a vital sign, contributing to the subsequent rise in the use of opioids to reduce pain. ${ }^{57}$ The emphasis on pain treatment may be further attributable to its influence on patient satisfaction, a parameter often linked to physician and institution reimbursement in the USA. ${ }^{58}$ However, evidence suggests that the emphasis on reducing pain and under-representation of opioid-related harms have contributed to the present overuse of opioid analgesics, particularly in the management of both acute and chronic noncancer pain. ${ }^{58,59}$ Moreover, growing evidence of opioid-related harms, including increased morbidity and mortality, puts into question the safety of extensive opioid use. ${ }^{60-62}$ Very few interventions specifically assessed the therapeutic benefit of ongoing analgesic treatment or monitored for cases in which harms related to opioid use outweighed the benefits. Therefore, the implementation of policies to reinforce the equal weighting of opioidrelated risks and benefits are warranted to facilitate a balanced approach to pain management.

Additionally, few studies reported the application of bestavailable evidence to guide the de-escalation of opioids once initiated. Recent literature suggest that a significant proportion of opioids prescribed during hospital admission are continued postdischarge, which may contribute to an increased risk of dependence and unintended harm. ${ }^{63}$ Interventions to deprescribe potentially inappropriate medications in older hospitalised adults have been shown to improve prescribing and clinical outcomes. ${ }^{64}$ However, limited evidence exists that applies similar principles to assess the ongoing need for opioid analgesia. Hence, there is scope for the development of policies to guide opioid deprescribing in cases where the risks of therapy outweigh the benefits to further contribute towards the safe and efficacious use of opioids.

This review supports the use of certain interventions to improve the safe and efficacious use of opioids, although the definition of opioid appropriateness varied, depending on the context in which the study was conducted. Earlier interventions conducted in the context of inadequate pain treatment encouraged opioid use as effective analgesic agents, before the focus of appropriate use shifted to potential opioid-related harms. ${ }^{65-67}$ No consensus could be established from the reviewed articles on the definition of opioid appropriateness. Thus, further studies are required to develop an internationally accepted definition of appropriate opioid use. 
Overall, the quality of evidence was low. No definitive conclusions could be drawn on efficacy on appropriate opioid use by intervention type. Although preliminary data suggest that interventions to improve appropriate opioid use may reduce hospital costs linked to opioid-related harms, further studies are needed to assess their net cost-effectiveness. Intervention complexity appeared to contribute to an extent towards effectiveness on improving patterns of opioid use. However, intervention efficacy may also be influenced by additional factors including retrospective study design, challenges in translating changes in practice to clinical outcome, and intrinsic methods of the interventions. There was a paucity of evidence to inform the feasibility of administrative-level involvement to influence hospital opioid use. Thus, further research is required to address the implementability of executive-level interventions to improve safe and efficacious opioid use in the hospital setting.

\section{5 | CONCLUSION}

Interventions involving academic detailing and education, especially when reinforced by performance feedback, show positive effects on appropriate opioid use for hospital inpatients. The development of policies to guide the deprescribing of opioids in cases where opioidrelated harms outweigh the benefits are warranted. Future studies on appropriate opioid use for hospital inpatients should focus on the effectiveness of interventions performed at the organisation-level to inform enhanced acute pain management using opioid analgesics.

\section{ACKNOWLEDGEMENTS}

The authors would like to acknowledge support provided by Edward Luca, the University of Sydney during search strategy development.

\section{CONFLICT OF INTEREST}

None declared.

\section{STATEMENT OF ORIGINALITY}

This work is submitted for publication in the British Journal of Clinical Pharmacology. The authors declare that this review has not been and, if accepted, will not be published in whole or in part in any other journal. All authors have read and approved the full manuscript in its submitted form.

\section{CONTRIBUTORS}

J.P. and D.G. conceived the study and designed the study protocol in collaboration with S.L. S.L. performed data collection and analysis. All authors contributed to its revision. S.L. drafted the manuscript and all authors read and approved the final manuscript.

\section{FUNDING}

D.G. is supported by the National Health and Medical Research Council (NHMRC) Dementia Leadership Fellowship. This had no role in the design of the study, data collection and analysis, or preparation of the manuscript.

\section{COMPETING INTERESTS}

None declared.

ETHICS APPROVAL

None required.

ORCID

Shania Liu (D) https://orcid.org/0000-0001-7047-4621

Danijela Gnjidic (D) https://orcid.org/0000-0002-9404-3401

Jessica Nguyen (D) https://orcid.org/0000-0002-1889-305X

Jonathan Penm (D) https://orcid.org/0000-0001-9606-7135

\section{REFERENCES}

1. Volkow N. Characteristics of Opioid Prescriptions in 2009. JAMA. 2011;305(13):1299-1301. https://doi.org/10.1001/jama.2011.401

2. National Institute for Health and Care Excellence. Pain management: Initial opioid prescriptions and likelihood of long-term opioid use. London: NICE; 2017.

3. Shafi S, Collinsworth A, Copeland L. Association of Opioid-Related Adverse Drug Events With Clinical and Cost Outcomes Among Surgical Patients in a Large Integrated Health Care Delivery System. JAMA Surg. 2018;153(8):782-782. https://doi.org/10.1001/jamasurg/2018. 2792

4. Davies E, Green C, Taylor S, Williamson P, Mottram D, Pirmohamed M. Adverse Drug Reactions in Hospital In-Patients: A Prospective Analysis of 3695 Patient-Episodes. PLoS ONE. 2009;4(2): e4439. https://doi.org/10.1371/journal.pone.0004439

5. Herzig S, Rothberg M, Cheung M, Ngo L, Marcantonio E. Opioid utilization and opioid-related adverse events in nonsurgical patients in US hospitals. J Hosp Med. 2013;9(2):73-81. https://doi.org/10.1002/ jhm.2102

6. American Geriatrics Society Panel on the Pharmacological Management of Persistent Pain in Older Persons. Pharmacologic Management of Persistent Pain in Older Persons. J Am Geriatr Soc. 2009;57(8):1331-1346.

7. Cerdá $\mathrm{M}$, Ransome $\mathrm{Y}$, Keyes $\mathrm{K}$, et al. Prescription opioid mortality trends in New York City, 1990-2006: Examining the emergence of an epidemic. Drug Alcohol Depend. 2013;132(1-2):53-62. https://doi. org/10.1016/j.drugalcdep.2012.12.027

8. Oderda G, Evans R, Lloyd J, et al. Cost of Opioid-Related Adverse Drug Events in Surgical Patients. J Pain Symptom Manage. 2003;25(3): 276-283. https://doi.org/10.1016/s0885-3924(02)00691-7

9. Pizzi L, Toner R, Foley $\mathrm{K}$, et al. Relationship Between Potential Opioid-Related Adverse Effects and Hospital Length of Stay in Patients Receiving Opioids After Orthopedic Surgery. Pharmacotherapy. 2012;32(6):502-514. https://doi.org/10.1002/j.1875-9114. 2012.01101

10. The Society of Hospital Medicine. Reducing Adverse Drug Events Related to Opioids Implementation Guide 2015. https://www. calhospital.org/sites/main/files/file-attachments/radeo implementation_guide.pdf. Accessed July 5, 2018.

11. Franklin G, Mai J, Turner J, Sullivan M, Wickizer T, Fulton-Kehoe D. Bending the prescription opioid dosing and mortality curves: Impact of the Washington State opioid dosing guideline. Am J Ind Med. 2011; 55(4):325-331. https://doi.org/10.1002/ajim.21998

12. Penm J, MacKinnon N, Mashni R, et al. Statewide cross-sectional survey of emergency departments' adoption and implementation of the Ohio opioid prescribing guidelines and opioid prescribing practices. BMJ Open. 2018;8(6):e020477. https://doi.org/10.1136/ bmjopen-2017-020477

13. Pomerleau A, Nelson L, Hoppe J, Salzman M, Weiss P, Perrone J. The Impact of Prescription Drug Monitoring Programs and Prescribing Guidelines on Emergency Department Opioid 
Prescribing: A Multi-Center Survey. Pain Med. 2016; 18(5):889-897. https://doi.org/10.1093/pm/pnw032

14. Tournebize J, Gibaja V, Muszczak A, Kahn J. Are Physicians Safely Prescribing Opioids for Chronic Noncancer Pain? A Systematic Review of Current Evidence. Pain Pract. 2015;16(3):370-383. https:// doi.org/10.1111/papr.12289

15. Eccleston $\mathrm{C}$, Fisher $\mathrm{E}$, Thomas $\mathrm{K}$, et al. Interventions for the reduction of prescribed opioid use in chronic non-cancer pain. Cochrane Database Syst Rev. 2017; 41(3):329-330. https://doi.org/10.1002/ 14651858.cd010323.pub3

16. Moher $D$, Shamseer $L$, Clarke $M$, et al. Preferred reporting items for systematic review and meta-analysis protocols (PRISMA-P) 2015 statement. Syst Rev. 2015;4(1):1.

17. Higgins JPT, Altman DG, Sterne JAC. Chapter 8: Assessing risk of bias in included studies Cochrane Handbook for Systematic Reviews of Interventions Version 5.1.0 (updated March 2011). The Cochrane Collaboration, 2011. Available from: https://www.handbook. cochrane.org.

18. Sterne JA, Hernán MA, Reeves $B C$, et al. ROBINS-I: a tool for assessing risk of bias in non-randomized studies of interventions. BMJ. 2016;355:i4919.

19. Lewin S, Hendry M, Chandler J, et al. Assessing the complexity of interventions within systematic reviews: development, content and use of a new tool (iCAT_SR). BMC Med Res Methodol. 2017;17(1):76. https://doi.org/10.1186/s12874-017-0349-x

20. Morrison RS, Flanagan S, Fischberg D, Cintron A, Siu AL. A novel interdisciplinary analgesic program reduces pain and improves function in older adults after orthopedic surgery. J Am Geriatr Soc. 2009 Jan; 57(1):1-10.

21. Bingle GJ, O'Connor TP, Evans WO, Detamore S. The effect of 'detailing' on physicians' prescribing behavior for postsurgical narcotic analgesia. Pain. 1991;45(2):171-173.

22. Neitzel JJ, Miller EH, Shepherd MF, Belgrade M. Improving pain management after total joint replacement surgery. Orthop Nurs. 1999;18(4):37-45.

23. Titsworth WL, Abram J, Guin P, et al. A prospective time-series quality improvement trial of a standardized analgesia protocol to reduce postoperative pain among neurosurgery patients. J Neurosurg. 2016; 125(6):1523-1532.

24. Benditz A, Greimel F, Auer P, et al. Can consistent benchmarking within a standardized pain management concept decrease postoperative pain after total hip arthroplasty? A prospective cohort study including 367 patients. J Pain Res. 2016;9:1205-1213.

25. Auyong DB, Allen CJ, Pahang JA, Clabeaux JJ, MacDonald KM, Hanson NA. Reduced length of hospitalization in primary total knee arthroplasty patients using an updated enhanced recovery after orthopedic surgery (ERAS) pathway. J Arthroplasty. 2015 Oct 1;30 (10):1705-1709.

26. Chan RPL, Chan WS. Outcome following introduction of a procedure specific pain management programme for caesarean section. Sri Lankan J Anaesth. 2018;26(1):39-44.

27. Humphries CA, Counsell DJ, Pediani RC, Close SL. Audit of opioid prescribing: the effect of hospital guidelines. Anaesthesia. $1997 \mathrm{Jul} ; 52$ (8):745-749.

28. Juhl IU, Bülow HH, Nielsen PR, Videbæk B, Sonnenschein C. Management of postoperative pain. An intervention study. Acta Anaesthesiol Scand. 1996;40(7):852-857.

29. Majumder A, Fayezizadeh M, Neupane R, Elliott HL, Novitsky YW. Benefits of multimodal enhanced recovery pathway in patients undergoing open ventral hernia repair. J Am Coll Surg. 2016 Jun 1;222 (6):1106-1115

30. Usichenko TI, Röttenbacher I, Kohlmann T, et al. Implementation of the quality management system improves postoperative pain treatment: A prospective pre-/post-interventional questionnaire study. $\mathrm{Br}$ J Anaesth. 2013:110(1):87-95.
31. Duncan K, Pozehl B. Effects of performance feedback on patient pain outcomes. Clin Nurs Res. 2000;9(4):379-397;98-401

32. Cui C, Wang LX, Li Q, Zaslansky R, Li L. Implementing a pain management nursing protocol for orthopaedic surgical patients: Results from a PAIN OUT project. J Clin Nurs. 2018;27(7-8):1684-1691.

33. Kjeldsen $\mathrm{L}$, Clemmensen $\mathrm{MH}$, Kronborg $\mathrm{C}$, et al. Evaluation of a controlled, national collaboration study on a clinical pharmacy service of screening for risk medications. Int J Clin Pharmacol. 2014;36(2): 368-376.

34. Bos JM, Bemt PM, Kievit W, et al. A multifaceted intervention to reduce drug-related complications in surgical patients. $\mathrm{Br} J \mathrm{Clin}$ Pharmacol. 2017;83(3):664-677.

35. Van Gulik L, Ahlers SJ, Brkic Z, et al. Improved analgesia after the realisation of a pain management programme in ICU patients after cardiac surgery. Eur J Anaesthesiol. 2010;27(10):900-905.

36. Chanques G, Jaber S, Barbotte $E$, et al. Impact of systematic evaluation of pain and agitation in an intensive care unit. Crit Care Med. 2006;34(6):1691-1699.

37. Olsen BF, Rustoen T, Sandvik L, Jacobsen M, Valeberg BT. Results of implementing a pain management algorithm in intensive care unit patients: The impact on pain assessment, length of stay, and duration of ventilation. J Crit Care. 2016;36:207-211.

38. Taylor DM, Fatovich DM, Finucci DP, et al. Best-practice pain management in the emergency department: A cluster-randomised, controlled, intervention trial. Emerg Med Australas. 2015;27(6): 549-557.

39. Moustafa F, Macian N, Giron F, Schmidt J, Pereira B, Pickering G. Intervention study with Algoplus: A pain behavioral scale for older patients in the emergency department. Pain Pract. 2017;17(5): 655-662.

40. Baehren DF, Marco CA, Droz DE, Sinha S, Callan EM, Akpunonu P. A Statewide Prescription Monitoring Program Affects Emergency Department Prescribing Behaviors. Ann Emerg Med. 2010;56:19-23. e3. https://doi.org/10.1016/j.annemergmed.2009.12.011

41. McAllister MW, Aaronson P, Spillane J, et al. Impact of prescription drug-monitoring program on controlled substance prescribing in the ED. Am J Emerg Med. 2015;33(6):781-785

42. Netherton SJ, Lonergan K, Wang D, McRae A, Lang E. Computerized physician order entry and decision support improves ED analgesic ordering for renal colic. Am J Emerg Med. 2014;32(9):958-961. https://doi.org/10.1016/j.ajem.2014.05.002

43. Muntlin Å, Carlsson M, Säfwenberg U, Gunningberg L. Outcomes of a nurse-initiated intravenous analgesic protocol for abdominal pain in an emergency department: A quasi-experimental study. Int J Nurs Stud. 2011;48(1):13-23.

44. Pierik JG, Berben SA, IJzerman MJ, et al. A nurse-initiated pain protocol in the ED improves pain treatment in patients with acute musculoskeletal pain. Int Emerg Nurs. 2016;27:3-10.

45. Manias E, Gibson SJ, Finch S. Testing an Educational Nursing Intervention for Pain Assessment and Management in Older People. Pain Med. 2011;12(8):1199-1215.

46. O'Sullivan D, O'Mahony D, O'Connor MN, et al. Prevention of Adverse Drug Reactions in Hospitalised Older Patients Using a Software-Supported Structured Pharmacist Intervention: A Cluster Randomised Controlled Trial. Drugs Aging. 2016;33(1):63-73.

47. Dalleur O, Boland B, Losseau C, et al. Reduction of potentially inappropriate medications using the STOPP criteria in frail older inpatients: A randomised controlled study. Drugs Aging. 2014;31(4): 291-298.

48. O'Connor MN, O'Sullivan D, Gallagher PF, Eustace J, Byrne S, O'Mahony D. Prevention of Hospital-Acquired Adverse Drug Reactions in Older People Using Screening Tool of Older Persons' Prescriptions and Screening Tool to Alert to Right Treatment Criteria: A Cluster Randomized Controlled Trial. J Am Geriatr Soc. 2016;64(8): 1558-1566. 
49. Urfer M, Elzi L, Dell-Kuster S, Bassetti S. Intervention to improve appropriate prescribing and reduce polypharmacy in elderly patients admitted to an internal medicine unit. PLoS ONE. 2016;11(11): e0166359.

50. Boothby LA, Wang LJ, Mayhew S, Chestnutt L. Academic detailing of meperidine at a teaching hospital. Hosp Pharm. 2003;38(1):30-35.

51. Shaw J, Harris P, Keogh G, Graudins L, Perks E, Thomas PS. Error reduction: academic detailing as a method to reduce incorrect prescriptions. Eur J Clin Pharmacol. 2003;59(8-9):697-699.

52. Akce M, Suneja A, Genord C, Singal B, Hopper JA. A multifactorial intervention for hospital opioid management. J Opioid Manag. 2014; 10(5):337-344

53. Paul JE, Bertram B, Antoni K, et al. Impact of a comprehensive safety initiative on patient-controlled analgesia errors. Anesthesiology. 2010; 113(6):1427-1432

54. Ferguson R, Williams ML, Beard B. Combining quality improvement and staff development efforts to decrease patient-controlled analgesia pump errors. J Nurses Staff Dev. 2010;26(5):E1-E4.

55. Whipple JK, Quebbeman EJ, Lewis KS, Gaughan LM, Gallup EL, Ausman RK. Identification of patient-controlled analgesia overdoses in hospitalized patients: computerized method of monitoring adverse events. Ann Pharmacother. 1994;28(May):655-658.

56. McEvoy T, Moore J, Generali J. Original article: Inpatient prescribing and monitoring of fentanyl transdermal systems: Adherence to safety regulations. Hosp Pharm. 2014;49(10):942-949.

57. American Pain Society Quality of Care Committee. Quality improvement guidelines for the treatment of acute pain and cancer pain. JAMA. 1995;274:1874-1880.

58. Zgierska A, Miller M, Rabago D. Patient Satisfaction, Prescription Drug Abuse, and Potential Unintended Consequences. JAMA. 2012; 307(13):1377-1378. https://doi.org/10.1001/jama.2012.419

59. Sullivan MD, Ballantyne JC. Must we reduce pain intensity to treat chronic pain? Pain. 2016;157(1):65-69.

60. King N, Fraser V, Boikos C, Richardson R, Harper S. Determinants of Increased Opioid-Related Mortality in the United States and Canada, 1990-2013: A Systematic Review. Am J Public Health. 2014;104(8): e32-e42.

61. Beaudoin F, Merchant R, Janicki A, McKaig D, Babu K. Preventing latrogenic Overdose: A Review of In-Emergency Department OpioidRelated Adverse Drug Events and Medication Errors. Ann Emerg Med. 2015;65(4):423-431.

62. Reitan J, Moleski R, Van Breda A, Adamson R, Lew I. Cost and Quality Implications of Opioid-Based Postsurgical Pain Control in Total Abdominal Hysterectomy: A Study of Cost Outliers and OpioidRelated Adverse Events. Hosp Pharm. 2012;47(11):855-862.

63. Hoppe JA, Kim H, Heard K. Association of emergency department opioid initiation with recurrent opioid use. Ann Emerg Med. 2015;65 (5):493-499. e494

64. Thillainadesan J, Gnjidic D, Green S, Hilmer S. Impact of Deprescribing Interventions in Oldxer Hospitalised Patients on Prescribing and Clinical Outcomes: A Systematic Review of Randomised Trials. Drugs Aging. 2018;35(4):303-319.

65. Foy R, Leaman B, McCrorie C, et al. Prescribed opioids in primary care: cross-sectional and longitudinal analyses of influence of patient and practice characteristics. BMJ Open. 2016;6(5):e010276. https:// doi.org/10.1136/bmjopen-2015-010276

66. Boudreau D, Von Korff M, Rutter CM, et al. Trends in long-term opioid therapy for chronic non-cancer pain. Pharmacoepidemiol Drug Saf. 2009;18(12):1166-1175.

67. Leong M, Murnion B, Haber PS. Examination of opioid prescribing in Australia from 1992 to 2007. Intern Med J. 2009;39(10):676-681.

68. National Health and Medical Research Council Australia. Levels of Evidence 2008. https://www.mja.com.au/sites/default/ files/NHMRC.levels.of.evidence.2008-09.pdf. Accessed December 5, 2018.
How to cite this article: Liu S, Gnjidic D, Nguyen J, Penm J.

Effectiveness of interventions on the appropriate use of opioids for noncancer pain among hospital inpatients: A systematic review. Br J Clin Pharmacol. 2020;86:210-243. https://doi.org/10.1111/bcp.14203

\section{APPENDIX A}

\section{A.1. | Database search terms}

MEDLINE (1960 to Present) (OvidSP).

1. exp Analgesics, Opioid/or exp Narcotics/. $\beta$

2. (acetyldihydrocodeine or alfentanil or allylprodine or alphamethylfentanyl or alphaprodine or benzylmorphine or betaprodine or buprenorphine or butorphanol or bremazocine or codeine or contin or dextromoramide or dextropropoxyphene or dezocine or diacetylmorphine or diamorphine or dihydrocodeine or dihydromorphine or dihydromorphone or diphenoxylate or dipipanone or enadoline or ethylketazocine or ethylmorphine or etonitazene or etorphine or fentanyl or heroin or hydrocodone or hydromorphin* or hydromorphone or ketazocine or ketobemidone or lefetamine or levomethadon or levomethadyl or levomethorphan* or levorphanol or loperamide or meperidine or meptazinol or methadone or methadyl or methylmorphine or morphin* or nalbuphine or narcotic* or nicocodeine or nicomorphine or normorphine or noscapin* or ohmefentanyl or opiate* or opioid* or opium or oripavine or oxycodone or oxycontin or oxymorphone or papaveretum or papaverin or pentazocine or percocet or peronine or pethidine or phenazocine or phencyclidine or pholcodine or piritramid* or prodine or promedol or propoxyphene or remifentanil or sufentanil or tapentadol or thebaine or tilidine).tw.

\section{1 or 2 .}

4. INPATIENTS/or inpatient*.mp. or (inpatient* adj2 hospital*). mp. or (inpatient* adj2 setting*).mp.

5. hospital.mp. or Hospitals/or (hospital* adj2 setting*).mp.

6. exp Hospital Departments/.

7. (acute adj2 care).mp. or acute disease/

8. emergency service, hospital/or trauma centers/or (emergency adj2 department).mp.

9.4 or 5 or 6 or 7 or 8 .

10. ((prescrib* adj2 interven*) or (approp* adj2 prescrib*)).mp.

11. medication errors/or inappropriate prescribing/or pharmacy service, hospital/.

12. Medication Therapy Management/.

13. "Drug Utilization Review"/or drug utili?ation review.mp. or Drug Utilization/or stewardship.mp.

14. drug monitor*.mp. or Drug Monitoring/.

15. Medication Systems, Hospital/

16. intervention*.ti. or (intervention* adj6 (clinician* or collaborat* or design* or doctor* or educa* or impact* or improve* or 
individuali* or interdisciplin* or multicomponent or multi-component or multidisciplin* or multi-disciplin* or multifacet* or multi-facet* or multimodal* or multi-modal* or pharma* or physician* or practitioner* or prescrib* or professional* or provider* or tailor* or target* or usual care)).ti,ab.

17. (adherence or alert* or benchmark* or (change adj3 treatment) or computer assist* or support or compute* or clinical decision* or dosing or formulary or guidance or guideline* or impact or justification or overuse or over-prescrib* or overprescrib* or underprescrib* or underprescrib* or pathway* or program* or programme* or (quality adj3 improv*) or reminder* or restriction* or unnecessary). ti.

18. 10 or 11 or 12 or 13 or 14 or 15 or 16 or 17.

19. 3 and 9 and 18.

20. limit 19 to (English language and humans).

\section{A.2. Appendix (i)}

Quality assessment summary of included randomised controlled trials using the Cochrane Risk of Bias Assessment Tool ${ }^{17}(n=4)$.

\begin{tabular}{|c|c|c|}
\hline $\begin{array}{l}\text { Study authors } \\
\text { Bias }\end{array}$ & \multicolumn{2}{|l|}{ Dalleur et al. ${ }^{47}$} \\
\hline Random sequence generation (selection bias) & Low risk of bias & $\begin{array}{l}\text { Selection through "simple randomisation using drawing of } \\
\text { lots" }\end{array}$ \\
\hline Allocation concealment (selection bias) & Low risk of bias & $\begin{array}{l}\text { "The IGCT nurse provided the evaluator with a list of the } \\
\text { patients included in the study, which did not specify } \\
\text { allocation group. The evaluator gathered data on the } \\
\text { primary outcome." }\end{array}$ \\
\hline Blinding of participants and personnel & Low risk of bias & $\begin{array}{l}\text { "The attending ward physician (who is responsible for } \\
\text { prescriptions during hospitalisation and at discharge), the } \\
\text { evaluator (OD), and the patients were blinded to group } \\
\text { assignment." }\end{array}$ \\
\hline Blinding of outcome assessment (detection bias) & Low risk of bias & Blinding of outcome assessment described in article. \\
\hline Other bias & N/A & N/A \\
\hline Overall quality assessment & \multicolumn{2}{|l|}{ Low risk of bias } \\
\hline Study authors & \multicolumn{2}{|l|}{ O'Connor et al. ${ }^{48}$} \\
\hline Bias & Judgement & Support for judgement \\
\hline Random sequence generation (selection bias) & High risk of bias & $\begin{array}{l}\text { "It was not a double-blinded study in which participants } \\
\text { and researchers were blinded to the group } \\
\text { randomization of each participant and the end points } \\
\text { being assessed by a blinded assessor. Similarly, the } \\
\text { intervention participants' attending doctors could not be } \\
\text { blinded to their randomization group, because they had } \\
\text { to decide whether to accept or reject individual } \\
\text { STOPP/START criteria" }\end{array}$ \\
\hline Blinding of outcome assessment (detection bias) & High risk of bias & Outcome assessment not blinded. \\
\hline Incomplete outcome data (attrition bias) & Unclear risk of bias & $\begin{array}{l}\text { Attrition is described but differences between patients } \\
\text { who completed and did not complete the trial was not } \\
\text { analysed }\end{array}$ \\
\hline Selective reporting (reporting bias) & Low risk of bias & $\begin{array}{l}\text { Comprehensive reporting of outcomes. The study protocol } \\
\text { is available and all study outcomes are prespecified. }\end{array}$ \\
\hline Other bias & N/A & N/A \\
\hline Overall quality assessment & High risk of bias & \\
\hline
\end{tabular}




\begin{tabular}{l} 
Study authors \\
\hline Bias
\end{tabular}

Random sequence generation (selection bias)
O'Sullivan et al. ${ }^{46}$

Judgement

Low risk of bias

\section{Support for judgement}

"We cluster-randomised the admitting consultants and their teams into 2 groups prior to study initiation, i.e. intervention or control consultants. At admission, we allocated patients to 1 of 2 groups, i.e. (1) usual pharmaceutical care (control group) or (2) the CDSS-supported SPRM intervention designed to optimise geriatric pharmaceutical care (intervention group), based on the particular consultant with primary responsibility for the patient's care during the index hospital admission. To avoid potentially biased selection of subjects into either arm of the study, we approached prospective trial patients in the order of their admission to the hospital to assess their eligibility for the trial."

\begin{tabular}{ll} 
Allocation concealment (selection bias) & High risk of bia \\
\hline Blinding of participants and personnel & High risk of bia
\end{tabular}

Allocation of participants and investigators was not concealed or randomised.

"Due to the nature of the intervention, it was not possible to blind participating attending doctors ...It was not possible for the intervention to be double- blinded due to its nature;"

\section{Blinding of outcome assessment (detection bias) Low risk of bias}

Low risk of bias
Incomplete outcome data (attrition bias)

Low risk of bias

N/A

Low risk of bias

Overall quality assessment

Study authors

Bias

Taylor et al. ${ }^{38}$

Judgement

Random sequence generation (selection bias)

High risk of bias

"The primary researcher recorded all documented new symptoms and clinical phenomena from every patient's medical records electronically and these were cross-referenced with the trigger list, thereby minimising (but not abolishing) potential observer bias. In addition, we sought to further attenuate observer bias by including only those ADRs corroborated by the medically trained ADR assessor who was blinded to the group allocation of each patient in the trial."

"34 patients (17 intervention and 17 control patients) died during their index hospital admission; we included these patients in the final analysis on the basis of adherence to the intention-to-treat principle."

Comprehensive reporting of outcomes. The study protocol is available and all study outcomes are prespecified.

N/A

\section{Support for judgement}

The study authors acknowledge that "patients were not individually randomised. However, the EDs were cluster randomised to early (5 EDs) and late (4 EDs) intervention clusters, using a computer-generated random number function. During periods when study staff were available (usually 0800-1800, 7 days/week), consecutive patients who met the study entrance criteria were recruited."

\begin{tabular}{ll} 
Allocation concealment (selection bias) & Unclear risk of bias \\
\hline Blinding of participants and personnel & Low risk of bias
\end{tabular}

Not described

As reported in the article, "patients were only advised of the study at follow up. This was deliberate in order to minimise the Hawthorne effect. Had patients been aware that they were enrolled in a pain management study, this may have affected their follow-up responses."

Blinding of outcome assessment (detection bias) Low risk of bias
"Patients were either telephoned or visited in the ward by a site investigator who was blinded to the data that was collected in the ED, including whether the patient had received 'adequate analgesia"' 


\begin{tabular}{|c|c|c|}
\hline $\begin{array}{l}\text { Study authors } \\
\text { Bias }\end{array}$ & \multicolumn{2}{|l|}{ Taylor et al. ${ }^{38}$} \\
\hline Incomplete outcome data (attrition bias) & Low risk of bias & $\begin{array}{l}\text { "In total, } 1527 \text { patients were recruited although follow-up } \\
\text { data were not available for } 210 \text { (13.8\%). Patients lost to } \\
\text { follow up differed only in that fewer were administered } \\
\text { any type of analgesia ( } 76.7 \text { vs } 82.8 \%, P=0.04) "\end{array}$ \\
\hline Other bias & $\mathrm{N} / \mathrm{A}$ & $\mathrm{N} / \mathrm{A}$ \\
\hline
\end{tabular}

\section{A.3. | Appendix (ii)}

Quality assessment summary of included nonrandomised controlled studies using the Risk Of Bias In Non-randomised Studies of Interventions tool ${ }^{18}(n=33)$.

\begin{tabular}{|c|c|c|}
\hline $\begin{array}{l}\text { Study authors } \\
\text { Bias }\end{array}$ & \multicolumn{2}{|l|}{ Akce et al. ${ }^{52}$} \\
\hline Bias due to confounding & Moderate risk of bias & $\begin{array}{l}\text { The study authors acknowledge the potential for } \\
\text { confounding factors; however, these have not been } \\
\text { controlled for by study design or statistical analyses. }\end{array}$ \\
\hline Bias in selection of participants into the study & Low risk of bias & Randomised selection of participants into the study. \\
\hline Bias due to missing data & Serious risk of bias & Attrition of data is described but not analysed. \\
\hline Bias in measurement of outcomes & Low risk of bias & $\begin{array}{l}\text { Double data abstraction and data entry to minimise bias in } \\
\text { measurement of outcomes. }\end{array}$ \\
\hline Bias & Judgement & Support for judgement \\
\hline Bias due to confounding & Low risk of bias & $\begin{array}{l}\text { Potential risk of bias due to confounding accounted for by } \\
\text { statistical analysis including logistic regression models }\end{array}$ \\
\hline Bias in selection of participants into the study & Low risk of bias & Consecutive selection of participants into the study \\
\hline Bias in classification of interventions & Low risk of bias & Intervention groups clearly defined \\
\hline $\begin{array}{l}\text { Bias due to deviations from intended } \\
\text { interventions }\end{array}$ & No information & $\begin{array}{l}\text { Potential deviations from intended interventions not } \\
\text { described. }\end{array}$ \\
\hline Bias due to missing data & Low risk of bias & No missing data reported. \\
\hline Bias in measurement of outcomes & Moderate risk of bias & Outcome assessors not blinded to intervention status. \\
\hline
\end{tabular}




\begin{tabular}{|c|c|c|}
\hline \multirow{2}{*}{$\begin{array}{l}\text { Study authors } \\
\text { Bias }\end{array}$} & \multicolumn{2}{|l|}{ Baehren et al. ${ }^{40}$} \\
\hline & Judgement & Support for judgement \\
\hline Bias due to confounding & Serious risk of bias & $\begin{array}{l}\text { Potential confounding factors not controlled for by study } \\
\text { design or statistical analyses. }\end{array}$ \\
\hline Bias in selection of participants into the study & Serious risk of bias & $\begin{array}{l}\text { The study authors acknowledge that "Enrolment was } \\
\text { based on a convenience sample" }\end{array}$ \\
\hline Bias in classification of interventions & Low risk of bias & Clear classification of intervention groups. \\
\hline $\begin{array}{l}\text { Bias due to deviations from intended } \\
\text { interventions }\end{array}$ & Serious risk of bias & $\begin{array}{l}\text { As reported in the article, "the number of patients treated } \\
\text { by each physician is not the same." }\end{array}$ \\
\hline Bias due to missing data & No information & Attrition of data not reported. \\
\hline Bias in measurement of outcomes & Low risk of bias & $\begin{array}{l}\text { "Subjects were identified only by the research assistants } \\
\text { who reviewed the triage information patients were } \\
\text { assigned a sequential number" }\end{array}$ \\
\hline Bias in selection of the reported result & Moderate risk of bias & $\begin{array}{l}\text { Primary outcomes clearly reported. Multiple outcome } \\
\text { measurements within secondary outcome domains. }\end{array}$ \\
\hline Overall quality assessment & \multicolumn{2}{|l|}{ Moderate risk of bias } \\
\hline Study authors & \multicolumn{2}{|l|}{ Benditz et al. ${ }^{24}$} \\
\hline Bias & Judgement & Support for judgement \\
\hline Bias due to confounding & Serious risk of bias & $\begin{array}{l}\text { Potential confounding factors not addressed by } \\
\text { experimental design or statistical analyses. Patients } \\
\text { informed of study but all received same intervention; } \\
\text { health care professionals had increased experience with } \\
\text { protocol over time. }\end{array}$ \\
\hline Bias in selection of participants into the study & Low risk of bias & $\begin{array}{l}\text { The study authors state "no patients were available on } \\
\text { Mondays, which may also represent some kind of } \\
\text { selection bias. ...Wards to be visited were randomized } \\
\text { daily by drawing a number to prevent selection bias." }\end{array}$ \\
\hline Bias in classification of interventions & Moderate risk of bias & Classification of interventions not clearly defined. \\
\hline $\begin{array}{l}\text { Bias due to deviations from intended } \\
\text { interventions }\end{array}$ & No information & $\begin{array}{l}\text { No information to describe potential deviations from } \\
\text { intended interventions. }\end{array}$ \\
\hline Bias due to missing data & Serious risk of bias & $\begin{array}{l}\text { As acknowledged in the article, "We have no information } \\
\text { about the excluded patients." }\end{array}$ \\
\hline Bias in measurement of outcomes & Low risk of bias & $\begin{array}{l}\text { The study authors state "To avoid any interviewer-patient } \\
\text { interaction bias, the nurse informed the patients that she } \\
\text { was working independently from the health care team, } \\
\text { that all information or judgment given in the interview } \\
\text { would be treated confidentially, and that participation } \\
\text { was voluntary. Data were anonymized after the } \\
\text { interview." }\end{array}$ \\
\hline Bias in selection of the reported result & Low risk of bias & $\begin{array}{l}\text { Primary and secondary outcome measurements reported in } \\
\text { article tables. }\end{array}$ \\
\hline Overall quality assessment & \multicolumn{2}{|l|}{ Moderate risk of bias } \\
\hline Study authors & \multicolumn{2}{|l|}{ Bingle et al. ${ }^{21}$} \\
\hline Bias & Judgement & Support for judgement \\
\hline Bias due to confounding & Serious risk of bias & $\begin{array}{l}\text { Potential confounding factors not addressed by } \\
\text { experimental design or statistical analyses }\end{array}$ \\
\hline Bias in selection of participants into the study & Serious risk of bias & $\begin{array}{l}\text { Potential bias introduced by selection of participants into } \\
\text { the study not controlled in the study. }\end{array}$ \\
\hline Bias in classification of interventions & No information & $\begin{array}{l}\text { Limited description of the differences between the } \\
3 \text { detailing interventions }\end{array}$ \\
\hline $\begin{array}{l}\text { Bias due to deviations from intended } \\
\text { interventions }\end{array}$ & Moderate risk of bias & $\begin{array}{l}\text { Intervention groups moderately defined, which may } \\
\text { introduce a certain degree of bias due to deviations of } \\
\text { intended interventions. }\end{array}$ \\
\hline
\end{tabular}




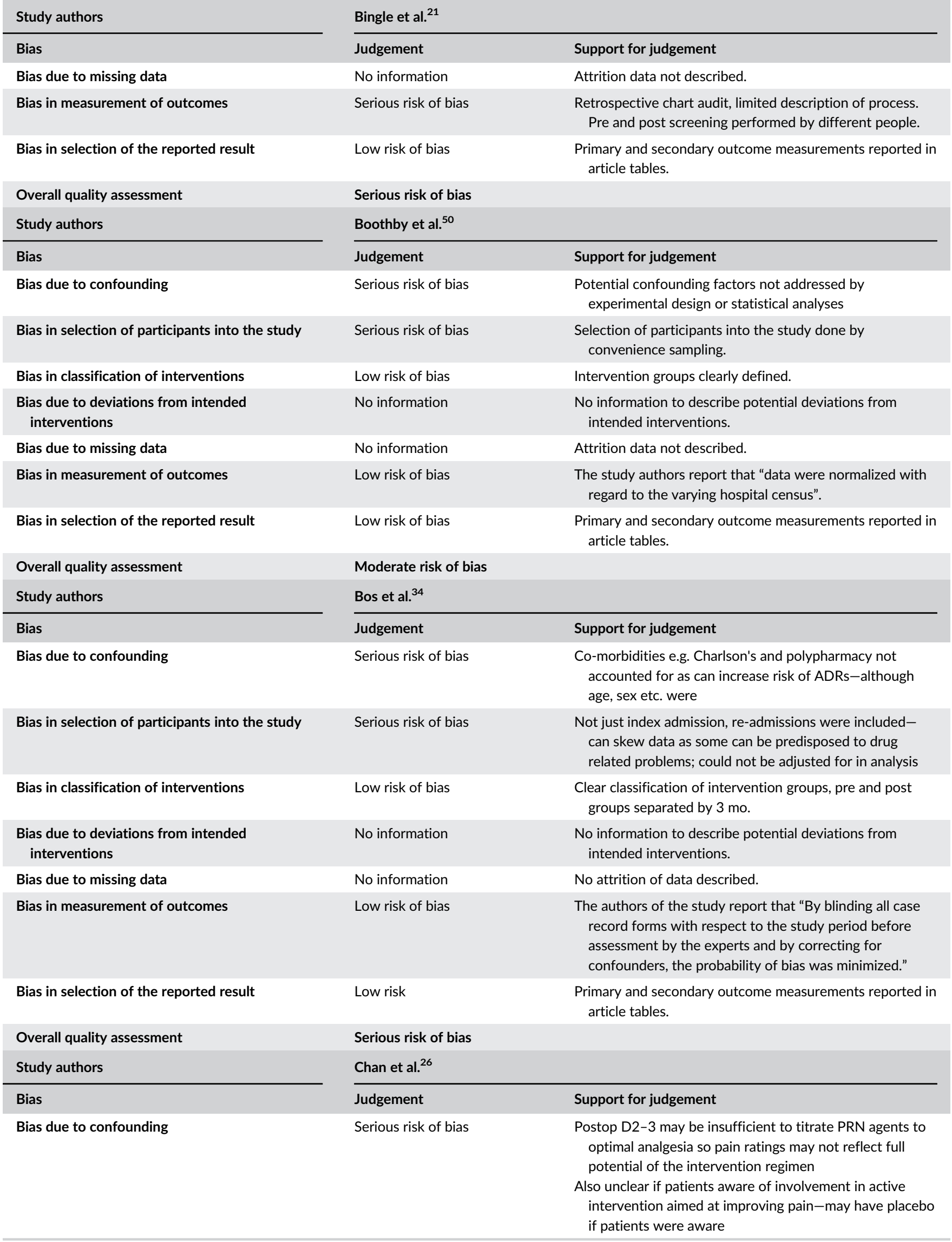




\begin{tabular}{|c|c|c|}
\hline \multirow{2}{*}{$\begin{array}{l}\text { Study authors } \\
\text { Bias }\end{array}$} & \multicolumn{2}{|l|}{ Chan et al. ${ }^{26}$} \\
\hline & Judgement & Support for judgement \\
\hline Bias in selection of participants into the study & Serious risk of bias & $\begin{array}{l}\text { Patients not randomised; recruitment periods were } \\
\text { different lengths }\end{array}$ \\
\hline Bias in classification of interventions & Low risk of bias & Fully prospective study \\
\hline $\begin{array}{l}\text { Bias due to deviations from intended } \\
\text { interventions }\end{array}$ & No information & Not described. \\
\hline Bias due to missing data & Serious risk of bias & $\begin{array}{l}\text { The authors acknowledge that "there are some missing } \\
\text { data in both surveys, especially the second } \\
\text { questionnaire." } 29.5 \% \text { missing data in the intervention } \\
\text { group (Group B). }\end{array}$ \\
\hline qBias in measurement of outcomes & Serious risk of bias & $\begin{array}{l}\text { Surveys completed by patients; risk of deviation or } \\
\text { subjective interpretation. Outcome assessors were not } \\
\text { blinded. }\end{array}$ \\
\hline Bias in selection of the reported result & No information & Not described. \\
\hline Overall quality assessment & \multicolumn{2}{|l|}{ Serious risk of bias } \\
\hline Study authors & \multicolumn{2}{|l|}{ Chanques et al. ${ }^{36}$} \\
\hline Bias & Judgement & Support for judgement \\
\hline Bias due to confounding & Low risk of bias & $\begin{array}{l}\text { Accounted for delirium and intensive care unit handicaps in } \\
\text { communicating pain. Healthcare professionals blinded to } \\
\text { results of assessments in control phase. }\end{array}$ \\
\hline Bias in selection of participants into the study & Low risk of bias & $\begin{array}{l}\text { Prospective, consecutive recruitment of participants into } \\
\text { the study. }\end{array}$ \\
\hline Bias in classification of interventions & Low risk of bias & Clear classification of interventions. \\
\hline $\begin{array}{l}\text { Bias due to deviations from intended } \\
\text { interventions }\end{array}$ & No information & $\begin{array}{l}\text { Strategies to address potential deviations from intended } \\
\text { interventions not adequately described. }\end{array}$ \\
\hline Bias due to missing data & Moderate risk of bias & Attrition data described, but no analysis was performed. \\
\hline Bias in measurement of outcomes & Serious risk of bias & $\begin{array}{l}\text { Potential for subjective measurement of pain scores. } \\
\text { Duration of intervention period was } 8 \text { weeks longer; } \\
\text { bigger sample size (but interrater reliability established). } \\
\text { Cannot blind healthcare professionals who administer } \\
\text { RASS and BPS }\end{array}$ \\
\hline Bias in selection of the reported result & No information & Not described. \\
\hline Overall quality assessment & \multicolumn{2}{|l|}{ Moderate risk of bias } \\
\hline Study authors & \multicolumn{2}{|l|}{ Cui et al. ${ }^{32}$} \\
\hline Bias & Judgement & Support for judgement \\
\hline Bias due to confounding & Serious risk of bias & $\begin{array}{l}\text { Postop main medication assessed by may be swayed as } \\
\text { surgeons informed of intervention; cannot guarantee } \\
\text { that they did not change practices per protocol-which } \\
\text { nurses may have picked up during their rounds together }\end{array}$ \\
\hline Bias in selection of participants into the study & Serious risk of bias & $\begin{array}{l}\text { Selection of participants into the study by convenience } \\
\text { sampling. }\end{array}$ \\
\hline Bias in classification of interventions & Low risk of bias & Clear classification of interventions. \\
\hline $\begin{array}{l}\text { Bias due to deviations from intended } \\
\text { interventions }\end{array}$ & No information & $\begin{array}{l}\text { Strategies to address potential deviations from intended } \\
\text { interventions not adequately described. }\end{array}$ \\
\hline Bias due to missing data & Low risk of bias & $\begin{array}{l}16 \text { and } 15 \text { nurses completed, though unclear how many } \\
\text { patients were recruited then excluded due to missing } \\
\text { data or other reasons }\end{array}$ \\
\hline Bias in measurement of outcomes & Serious risk of bias & $\begin{array}{l}\text { Questionnaire measurement of outcomes; potential for } \\
\text { subjective interpretation and response. }\end{array}$ \\
\hline Bias in selection of the reported result & No information & Not described. \\
\hline Overall quality assessment & Moderate risk of bias & \\
\hline
\end{tabular}




\begin{tabular}{|c|c|c|}
\hline Study authors & Duncan and Pozehl ${ }^{31}$ & \\
\hline Bias & Judgement & Support for judgement \\
\hline Bias due to confounding & Serious risk of bias & $\begin{array}{l}\text { Potential confounding factors not addressed by } \\
\text { experimental design or statistical analyses }\end{array}$ \\
\hline Bias in selection of participants into the study & Moderate risk of bias & Retrospective audit of patient medical records. \\
\hline Bias in classification of interventions & Low risk of bias & Clear classification of interventions. \\
\hline $\begin{array}{l}\text { Bias due to deviations from intended } \\
\text { interventions }\end{array}$ & No information & $\begin{array}{l}\text { Strategies to address potential deviations from intended } \\
\text { interventions not adequately described. }\end{array}$ \\
\hline Bias due to missing data & Moderate risk of bias & Attrition data described, but no analysis was performed \\
\hline Bias in measurement of outcomes & Serious risk of bias & $\begin{array}{l}\text { Self-reported pain intensity ratings; potential for subjective } \\
\text { measurement. }\end{array}$ \\
\hline Bias in selection of the reported result & No information & Not described. \\
\hline Overall quality assessment & Moderate risk of bias & \\
\hline Study authors & Ferguson et al. ${ }^{54}$ & \\
\hline Bias & Judgement & Support for judgement \\
\hline Bias due to confounding & Serious risk of bias & $\begin{array}{l}\text { Confounding factors acknowledged but could not be } \\
\text { controlled for due to the nature of the hospital setting. }\end{array}$ \\
\hline Bias in selection of participants into the study & Low risk of bias & $\begin{array}{l}\text { All patient-controlled analgesia (PCA) errors in hospital } \\
\text { over set period. }\end{array}$ \\
\hline Bias in classification of interventions & Low risk of bias & Intervention groups clearly defined. \\
\hline $\begin{array}{l}\text { Bias due to deviations from intended } \\
\text { interventions }\end{array}$ & Serious risk of bias & $\begin{array}{l}\text { Acknowledged potential for deviations from intended } \\
\text { interventions. }\end{array}$ \\
\hline Bias due to missing data & No information & Missing data not reported. \\
\hline Bias in measurement of outcomes & Low risk of bias & $\begin{array}{l}\text { Data PCA errors were objective and carried a lower } \\
\text { potential for subjective interpretation. }\end{array}$ \\
\hline Bias in selection of the reported result & No information & Not described. \\
\hline Overall quality assessment & Moderate risk of bias & \\
\hline Study authors & Humphries et al. ${ }^{27}$ & \\
\hline Bias & Judgement & Support for judgement \\
\hline Bias due to confounding & Serious risk of bias & $\begin{array}{l}\text { No adjustments made to account for potential } \\
\text { confounding factors. }\end{array}$ \\
\hline Bias in selection of participants into the study & Low risk of bias & All eligible patients included in analysis. \\
\hline Bias in classification of interventions & Low risk of bias & Intervention group clearly defined. \\
\hline $\begin{array}{l}\text { Bias due to deviations from intended } \\
\text { interventions }\end{array}$ & No information & $\begin{array}{l}\text { Potential deviations from intended interventions not } \\
\text { described. }\end{array}$ \\
\hline Bias due to missing data & Low risk of bias & Study authors report no attrition of data. \\
\hline Bias in measurement of outcomes & Moderate risk of bias & Outcome assessors not blinded to intervention status. \\
\hline Bias in selection of the reported result & No information & \\
\hline Overall quality assessment & Moderate risk of bias & \\
\hline Study authors & Juhl et al. ${ }^{28}$ & \\
\hline Bias & Judgement & Support for judgement \\
\hline Bias due to confounding & Serious risk of bias & $\begin{array}{l}\text { Measurement of pain scores depends on the day which } \\
\text { postoperative patients were interviewed; was not } \\
\text { consistent between patients nor between pre-post } \\
\text { intervention periods. }\end{array}$ \\
\hline Bias in selection of participants into the study & Moderate risk of bias & $\begin{array}{l}\text { Prospective and consecutive patient inclusion. However, } \\
\text { nurses' participation was voluntary, which is susceptible } \\
\text { to volunteer bias. }\end{array}$ \\
\hline Bias in classification of interventions & Low risk of bias & Prospective study and clear pre-post periods. \\
\hline
\end{tabular}




\begin{tabular}{|c|c|c|}
\hline Study authors & Juhl et al. ${ }^{28}$ & \\
\hline Bias & Judgement & Support for judgement \\
\hline $\begin{array}{l}\text { Bias due to deviations from intended } \\
\text { interventions }\end{array}$ & Low risk & $\begin{array}{l}\text { Intervention groups clearly defined to minimise deviation } \\
\text { from intended interventions. }\end{array}$ \\
\hline Bias due to missing data & Moderate risk of bias & Attrition described but no analysis performed. \\
\hline Bias in measurement of outcomes & Moderate risk of bias & $\begin{array}{l}\text { Nurses who assessed subjective pain could not be blinded; } \\
\text { good that McGill Pain Questionnaire translated by } \\
3 \text { qualified people }\end{array}$ \\
\hline Bias in selection of the reported result & Moderate risk of bias & $\begin{array}{l}\text { Reporting of anaesthetists' vs surgeons' prescribing } \\
\text { patterns were nonconsistent (converse figures reported) }\end{array}$ \\
\hline Overall quality assessment & Moderate risk of bias & \\
\hline Study authors & Kjeldsen et al. ${ }^{33}$ & \\
\hline Bias & Judgement & Support for judgement \\
\hline Bias due to confounding & Serious risk of bias & $\begin{array}{l}\text { Diff number of patients treated with NSAIDs (one of the } \\
\text { risk drugs) which can affect (opioid) analgesia } \\
\text { requirements and possibly subsequent recs (Table 1) }\end{array}$ \\
\hline Bias in selection of participants into the study & Low risk of bias & $\begin{array}{l}\text { Controlled prospective study design, analysis performed on } \\
2 \text { groups to ensure similar cohorts. }\end{array}$ \\
\hline Bias in classification of interventions & Low risk of bias & $\begin{array}{l}\text { "To ensure standardized interventions, an information } \\
\text { sheet was developed for each of the risk medications" }\end{array}$ \\
\hline $\begin{array}{l}\text { Bias due to deviations from intended } \\
\text { interventions }\end{array}$ & No information & $\begin{array}{l}\text { Strategies to address potential deviations from intended } \\
\text { interventions not adequately described. }\end{array}$ \\
\hline Bias due to missing data & Moderate risk of bias & $\begin{array}{l}\text { Reasons for exclusion; differs slightly between the } \\
2 \text { groups }\end{array}$ \\
\hline Bias in measurement of outcomes & Low risk of bias & Comprehensive reporting of outcomes \\
\hline Bias in selection of the reported result & Low risk of bias & Selection of reported results addressed \\
\hline Overall quality assessment & Serious risk of bias & \\
\hline Study authors & Majumder et al. ${ }^{29}$ & \\
\hline Bias & Judgement & Support for judgement \\
\hline Bias due to confounding & Moderate risk of bias & $\begin{array}{l}\text { Confounding variables are addressed to an extent by study } \\
\text { design (e.g. restriction of included patients). }\end{array}$ \\
\hline Bias in selection of participants into the study & Low risk of bias & Consecutive selection of participants into the study. \\
\hline Bias in classification of interventions & Low risk of bias & Intervention groups clearly defined. \\
\hline $\begin{array}{l}\text { Bias due to deviations from intended } \\
\text { interventions }\end{array}$ & No information & $\begin{array}{l}\text { Potential deviations from intended interventions not } \\
\text { described. }\end{array}$ \\
\hline Bias due to missing data & Low risk of bias & Study authors report no attrition of data. \\
\hline Bias in measurement of outcomes & Moderate risk of bias & $\begin{array}{l}\text { Outcome assessors not blinded to intervention status of } \\
\text { the participant. }\end{array}$ \\
\hline Bias in selection of the reported result & Low risk of bias & $\begin{array}{l}\text { Reported results reflect predefined primary and secondary } \\
\text { outcome measures. }\end{array}$ \\
\hline Overall quality assessment & Low risk of bias & \\
\hline Study authors & Manias et al. ${ }^{45}$ & \\
\hline Bias & Judgement & Support for judgement \\
\hline Bias due to confounding & Moderate risk of bias & $\begin{array}{l}\text { Potential confounding factors addressed to an extent by } \\
\text { study design. }\end{array}$ \\
\hline Bias in selection of participants into the study & Low risk of bias & Consecutive patient recruitment into the study. \\
\hline Bias in classification of interventions & Low risk of bias & Clear classification of interventions. \\
\hline $\begin{array}{l}\text { Bias due to deviations from intended } \\
\text { interventions }\end{array}$ & No information & $\begin{array}{l}\text { Strategies to address potential deviations from intended } \\
\text { interventions not adequately described. }\end{array}$ \\
\hline Bias due to missing data & Low risk of bias & No missing data reported. \\
\hline
\end{tabular}




Study authors
Bias

Bias in measurement of outcomes

Bias in selection of the reported result

Overall quality assessment

Study authors

\section{Bias}

Bias due to confounding

Bias in selection of participants into the study

Bias in classification of interventions

Bias due to deviations from intended interventions

Bias due to missing data

Bias in measurement of outcomes

Bias in selection of the reported result

Overall quality assessment

Study authors

Bias

Bias due to confounding

Bias in selection of participants into the study

Bias in classification of interventions

Bias due to deviations from intended interventions

Bias due to missing data

Bias in measurement of outcomes

Bias in selection of the reported result
Manias et al. $^{45}$

Judgement

Low risk of bias

\section{Support for judgement}

The study authors report "The research assistant who collected data from both groups was blinded to group assignment. In addition, nurses in each hospital were not informed about their allocated group."

No information

Not described.

Low risk of bias

McAllister et al. ${ }^{41}$

Judgement

Serious risk of bias

Low risk of bias

Low risk of bias

No information

Low risk of bias

No information

Moderate risk of bias

McEvoy et al. ${ }^{56}$

Judgement

Serious risk of bias

Low risk of bias

Low risk of bias

No information

Low risk of bias

Low risk of bias

Serious risk of bias

\section{Support for judgement}

Potential confounding factors not addressed by experimental design or statistical analyses

All eligible participants included into the study.

Clear classification of interventions.

Strategies to address potential deviations from intended interventions not adequately described.

Missing data not described.

Clear documentation of outcome measurement.

Support for judgement

Potential confounding factors not addressed by experimental design or statistical analyses

Retrospective analysis of electronic medication orders.

Clear classification of intervention groups.

Strategies to address potential deviations from intended interventions not adequately described.

Study authors reported no missing data.

Clear documentation of outcome measurement.

The authors acknowledge that "the duration of
No information

Not described postintervention assessment and sample size were not the same as the preintervention assessment. This may have affected the overall results due to variance in prescribing patterns."

\section{Moderate risk of bias}

Morisson et al. ${ }^{20}$

\section{Study authors}

Bias

Bias due to confounding

Judgement

Low risk of bias

Low risk of bias

Low risk of bias

No information

Low risk of bias

Low risk of bias

\section{Support for judgement}

Study design involved propensity score matching with control participants. Statistical analyses to control for confounding factors included logistic regression models.

All eligible participants were enrolled in the study.

Intervention groups clearly defined.

Potential deviations from intended interventions not described.

Details of subject enrolment clearly outlined and no other missing data reported.

The study was double-blinded. Participants were not informed as to whether they were enrolled in the
Bias in measurement of outcomes 


$\begin{array}{lll}\text { Study authors } & \text { Morisson et al. } & \\ \text { Bias } & \text { Judgement }\end{array}$

Bias in selection of the reported result

Low risk of bias

\section{Overall quality assessment}

Study authors

Bias

Bias due to confounding

Bias in selection of participants into the study

\section{Bias in classification of interventions \\ Bias due to deviations from intended interventions \\ Bias due to missing data}

Bias in measurement of outcomes

\section{Low risk of bias}

Moustafa et al. ${ }^{39}$

\section{Judgement}

Serious risk of bias

Moderate risk of bias

Low risk of bias

Serious risk of bias
No information

\section{Support for judgement}

intervention or control unit and outcome assessors were blinded to participant group.

Primary and secondary outcome measurements reported in article tables.
Low risk of bias

\begin{tabular}{l} 
Bias in selection of the reported result \\
Overall quality assessment \\
Study authors \\
\hline Bias
\end{tabular}

Bias due to confounding

Bias in selection of participants into the study
No information

\section{Serious risk of bias}

Muntlin et al. $^{43}$

\section{Judgement}

Serious risk of bias

Serious risk of bias

\section{Support for judgement}

Potential confounding factors not addressed by experimental design or statistical analyses

Prospective, consecutive selection of participants into the study.

Classification of interventions not explicitly described.

Strategies to address potential deviations from intended interventions not adequately described.

No attrition of data ( $100 \%$ pain assessment performed)

The study authors acknowledge "ED personnel were aware (in the second phase only) of the main outcome of the study and it is likely that the Hawthorne effect had an impact on pain assessment, but it did not so much on analgesics treatment."

Not described.

\section{Support for judgement}

Potential confounding factors not addressed by experimental design or statistical analyses

The authors report "Patients were approached to take part in the study $24 \mathrm{~h}$ a day, weekdays and weekends until the desired number of patients had been included." Convenience sampling may introduce bias into the study.

\begin{tabular}{|c|c|c|}
\hline Bias in classification of interventions & Serious risk of bias & $\begin{array}{l}\text { Clear classification of interventions, however, phases } B \text { and } \\
\text { A2 were not as explicitly described as A1. }\end{array}$ \\
\hline $\begin{array}{l}\text { Bias due to deviations from intended } \\
\text { interventions }\end{array}$ & No information & $\begin{array}{l}\text { No information to describe potential deviations from } \\
\text { intended interventions. }\end{array}$ \\
\hline Bias due to missing data & Moderate risk of bias & $\begin{array}{l}\text { Excluded data is described, however, differences between } \\
\text { included and excluded patients were not analysed }\end{array}$ \\
\hline Bias in measurement of outcomes & Serious risk of bias & $\begin{array}{l}\text { Questionnaire reporting of outcomes; potential for } \\
\text { discrepancies between researchers }\end{array}$ \\
\hline Bias in selection of the reported result & No information & Not described. \\
\hline Overall quality assessment & Serious risk of bias & \\
\hline Study authors & Neitzel et al. $^{22}$ & \\
\hline Bias & Judgement & Support for judgement \\
\hline Bias due to confounding & Serious risk of bias & $\begin{array}{l}\text { Potential confounding factors not addressed by } \\
\text { experimental design or statistical analyses. Patient pain } \\
\text { experience may affect length of stay. }\end{array}$ \\
\hline Bias in selection of participants into the study & Serious risk of bias & $\begin{array}{l}\text { Selection of participants into the study by convenience } \\
\text { sampling. }\end{array}$ \\
\hline Bias in classification of interventions & Low risk of bias & Intervention groups clearly described. \\
\hline
\end{tabular}




\begin{tabular}{|c|c|c|}
\hline \multirow{2}{*}{$\begin{array}{l}\text { Study authors } \\
\text { Bias }\end{array}$} & \multicolumn{2}{|l|}{ Neitzel et al. ${ }^{22}$} \\
\hline & Judgement & Support for judgement \\
\hline $\begin{array}{l}\text { Bias due to deviations from intended } \\
\text { interventions }\end{array}$ & No information & $\begin{array}{l}\text { Strategies to address potential deviations from intended } \\
\text { interventions not adequately described. }\end{array}$ \\
\hline Bias due to missing data & Low risk of bias & Reasonably complete data collection \\
\hline Bias in measurement of outcomes & Moderate risk of bias & $\begin{array}{l}\text { Outcome assessors not blinded to the intervention status } \\
\text { of the participants. Provider survey is potentially } \\
\text { subjective. }\end{array}$ \\
\hline Bias in selection of the reported result & No information & Not described \\
\hline Overall quality assessment & \multicolumn{2}{|l|}{ Moderate risk of bias } \\
\hline Study authors & \multicolumn{2}{|l|}{ Netherton et al. ${ }^{42}$} \\
\hline Bias & Judgement & Support for judgement \\
\hline Bias due to confounding & Serious risk of bias & $\begin{array}{l}\text { The authors acknowledge "We have not been able to } \\
\text { adjust for confounders; so the increase in ketorolac use } \\
\text { seen in Calgary EDs may be due to secular changes, that } \\
\text { is, physician knowledge about ketorolac use for acute } \\
\text { pain, or due to an influx of newly trained ED physicians } \\
\text { who may have been familiar with its use in their } \\
\text { residency training programs" }\end{array}$ \\
\hline Bias in selection of participants into the study & Low risk of bias & Random selection of participants into the study. \\
\hline Bias in classification of interventions & Low risk of bias & Clear classification of interventions. \\
\hline $\begin{array}{l}\text { Bias due to deviations from intended } \\
\text { interventions }\end{array}$ & No information & Not described. \\
\hline Bias due to missing data & Moderate risk of bias & $\begin{array}{l}\text { Attrition data described, but no analysis performed; } \\
\text { "Excluding patients arriving by Emergency Medical } \\
\text { Service may have led to the exclusion of the most severe } \\
\text { presentations of renal colic." }\end{array}$ \\
\hline Bias in measurement of outcomes & Moderate risk of bias & $\begin{array}{l}\text { Outcome assessors were not blinded to the intervention } \\
\text { status of the study participants. }\end{array}$ \\
\hline Bias in selection of the reported result & No information & Not described. \\
\hline Overall quality assessment & \multicolumn{2}{|l|}{ Moderate risk of bias } \\
\hline Study authors & \multicolumn{2}{|l|}{ Olsen et al. ${ }^{37}$} \\
\hline Bias & Judgement & Support for judgement \\
\hline Bias due to confounding & Serious risk of bias & $\begin{array}{l}\text { The authors acknowledge "A pre-post intervention design } \\
\text { has weaknesses, as confounding variables could } \\
\text { influence the outcome, but differences in baseline } \\
\text { variables between groups were controlled, using } \\
\text { regression analysis" }\end{array}$ \\
\hline Bias in selection of participants into the study & Serious risk of bias & $\begin{array}{l}\text { Non-consecutive recruitment of eligible patients into the } \\
\text { study. }\end{array}$ \\
\hline Bias in classification of interventions & Low risk of bias & Clear classification of interventions. \\
\hline $\begin{array}{l}\text { Bias due to deviations from intended } \\
\text { interventions }\end{array}$ & No information & $\begin{array}{l}\text { Potential deviation from intended interventions not } \\
\text { adequately described. }\end{array}$ \\
\hline Bias due to missing data & Moderate risk of bias & Attrition data described, but no analysis was performed. \\
\hline Bias in measurement of outcomes & Serious risk of bias & $\begin{array}{l}\text { Potential for subjective pain assessment; "we did not have } \\
\text { independent observers assessing pain in the control } \\
\text { group" }\end{array}$ \\
\hline Bias in selection of the reported result & Serious risk of bias & $\begin{array}{l}\text { No results re pain events or even any of the } 3 \text { pain tools; } \\
\text { high risk of selective reporting }\end{array}$ \\
\hline
\end{tabular}




\begin{tabular}{lll} 
Study authors & & Paul et al. ${ }^{53}$ \\
\hline Bias & & Judgement \\
Bias due to confounding & Low risk of bias
\end{tabular}

Bias in selection of participants into the study

Low risk of bias

\section{Support for judgement}

The authors report that potential confounding factors were addressed. "Cases where the cause of the critical incident was attributed to patient factors were excluded from this study"

"Two reviewers (B.B., A.M.) obtained and examined all Hamilton Health Sciences Acute Pain Service (HHS APS) critical incident reports $(n=642)$ dating from 1 February 2002 to 28 February 2009. Each report was reviewed to determine whether the event involved a PCA setup, programming, or administration error. Any discrepancies were resolved through consensus or discussion with a third reviewer"

\begin{tabular}{|c|c|c|}
\hline Bias in classification of interventions & Low risk of bias & $\begin{array}{l}\text { Classification of interventions between intervention and } \\
\text { control groups explicitly described. }\end{array}$ \\
\hline $\begin{array}{l}\text { Bias due to deviations from intended } \\
\text { interventions }\end{array}$ & No information & $\begin{array}{l}\text { Potential deviation from intended interventions not } \\
\text { adequately described. }\end{array}$ \\
\hline Bias due to missing data & No information & Missing data not described. \\
\hline Bias in measurement of outcomes & Moderate risk of bias & $\begin{array}{l}\text { Outcome assessors not blinded to the intervention status } \\
\text { of participants. }\end{array}$ \\
\hline Bias in selection of the reported result & No information & Not described \\
\hline Overall quality assessment & Low risk of bias & \\
\hline Study authors & Pierik et al. ${ }^{44}$ & \\
\hline Bias & Judgement & Support for judgement \\
\hline Bias due to confounding & Serious risk of bias & $\begin{array}{l}\text { The study authors acknowledge that "There are a number } \\
\text { of important potential confounding factors, e.g. severity } \\
\text { of injury, knowledge and experience of pain } \\
\text { management, which were not measured and may have } \\
\text { differed in both periods No adjustments could be made." }\end{array}$ \\
\hline Bias in selection of participants into the study & Low risk of bias & $\begin{array}{l}\text { Consecutive patient recruitment of participants into the } \\
\text { study. }\end{array}$ \\
\hline Bias in classification of interventions & Low risk of bias & Clear classification of interventions. \\
\hline $\begin{array}{l}\text { Bias due to deviations from intended } \\
\text { interventions }\end{array}$ & No information & $\begin{array}{l}\text { Potential deviations from intended interventions not } \\
\text { adequately described. }\end{array}$ \\
\hline Bias due to missing data & Low risk of bias & No attrition of data. \\
\hline Bias in measurement of outcomes & Serious risk of bias & $\begin{array}{l}\text { The authors report "The percentage of patients who were } \\
\text { actually administered analgesics might be } \\
\text { underestimated. Even though the ED staff was } \\
\text { instructed to list all medications, some may have } \\
\text { neglected to do so, especially for over-the-counter } \\
\text { analgesics." }\end{array}$ \\
\hline Bias in selection of the reported result & Low risk of bias & Objective selection of reported results described. \\
\hline Overall quality assessment & Moderate risk of bias & \\
\hline Study authors & Shaw et al. ${ }^{51}$ & \\
\hline Bias & Judgement & Support for judgement \\
\hline Bias due to confounding & Serious risk of bias & $\begin{array}{l}\text { Potential confounding factors not addressed by } \\
\text { experimental design or statistical analyses }\end{array}$ \\
\hline Bias in selection of participants into the study & Low risk of bias & $\begin{array}{l}\text { Analysis of all eligible prescription error rates according to } \\
\text { predefined criteria. }\end{array}$ \\
\hline Bias in classification of interventions & Low risk of bias & $\begin{array}{l}\text { Clear intervention methodology and classification } \\
\text { described. }\end{array}$ \\
\hline $\begin{array}{l}\text { Bias due to deviations from intended } \\
\text { interventions }\end{array}$ & Low risk of bias & $\begin{array}{l}\text { Hard copy material provided to study participants, unlikely } \\
\text { to produce deviation across participants. }\end{array}$ \\
\hline
\end{tabular}




\begin{tabular}{l} 
Study authors \\
\hline Bias \\
\hline Bias due to missing data \\
Bias in measurement of outcomes \\
Bias in selection of the reported result \\
\hline Overall quality assessment \\
\hline Study authors \\
\hline Bias
\end{tabular}

Bias due to confounding

\section{Bias in classification of interventions \\ Bias due to deviations from intended interventions}

Bias due to missing data

Bias in measurement of outcomes

Bias in selection of the reported result

Overall quality assessment

Study authors

\section{Bias}

Bias due to confounding

\section{Bias in selection of participants into the study}

Bias in classification of interventions

Bias due to deviations from intended interventions

Bias due to missing data

Bias in measurement of outcomes

Bias in selection of the reported result

\begin{tabular}{l} 
Overall quality assessment \\
Study authors \\
\hline Bias
\end{tabular}

Bias due to confounding
Shaw et al. ${ }^{51}$

Judgement

No information

Low risk of bias

Unclear

Low risk of bias

Titsworth et al. ${ }^{23}$

Judgement

Serious risk of bias

Low risk of bias

Low risk of bias

Low risk of bias

Moderate risk of bias

Serious risk of bias

No information

Moderate risk of bias

Urfer et al. ${ }^{49}$

Judgement

Low risk of bias

Low risk of bias

Low risk of bias

No information

Moderate risk of bias

Low risk of bias

Moderate risk of bias

\section{Support for judgement}

Missing data not described.

Quantitative analysis of prescription error rates.

Not described

\section{Support for judgement}

Potential confounding factors not addressed by experimental design or statistical analyses. Patient questionnaire performed, no blinding of patients described, potential for patients to answer more positively due to nonanonymity

"Systematic random sampling was used to identify every 10th postoperative neurosurgical patient admitted preintervention and every 17 th patient postintervention"

Explicit classification of interventions.

Intended interventions were clearly documented to minimise risk of bias introduced by deviation from intervention.

Excluded data is described, however, differences between included and excluded patients were not analysed

"Nurses collected pain scores and were aware of the initiative; this could have potentially influenced patient-reporting practices, resulting in response bias."

Not described. 


\begin{tabular}{|c|c|c|}
\hline Study authors & Usichenko et al. ${ }^{30}$ & \\
\hline Bias & Judgement & Support for judgement \\
\hline Bias in selection of participants into the study & Low risk of bias & $\begin{array}{l}\text { Prospective, consecutive recruitment of participants into } \\
\text { the study }\end{array}$ \\
\hline Bias in classification of interventions & Low risk of bias & Clear classification of intervention groups. \\
\hline $\begin{array}{l}\text { Bias due to deviations from intended } \\
\text { interventions }\end{array}$ & Low risk of bias & $\begin{array}{l}\text { Interventions clearly defined and no deviation from } \\
\text { intended interventions reported. }\end{array}$ \\
\hline Bias due to missing data & Low risk of bias & $\begin{array}{l}91 \% \text { and } 85 \% \text { survey completion rate; proportions similar } \\
\text { across groups }\end{array}$ \\
\hline Bias in measurement of outcomes & Moderate risk of bias & $\begin{array}{l}\text { Potential for subjective reporting of pain in surveys using } \\
\text { visual rating scale }\end{array}$ \\
\hline Bias in selection of the reported result & Moderate risk of bias & Power calculations done \\
\hline Overall quality assessment & Moderate risk of bias & \\
\hline Study authors & VanGulik et al. ${ }^{35}$ & \\
\hline Bias & Judgement & Support for judgement \\
\hline Bias due to confounding & Serious risk of bias & $\begin{array}{l}\text { Nurses not blinded to intervention; bedside manner or } \\
\text { attention to detail/pain may become more astute as they } \\
\text { gain more experience with pain medication especially } \\
\text { over } 15 \text { mo. }\end{array}$ \\
\hline Bias in selection of participants into the study & Unclear risk of bias & $\begin{array}{l}\text { Unclear if patient selection was random or consecutive for } \\
\text { total knee arthroplasty patients. }\end{array}$ \\
\hline Bias in classification of interventions & Low risk of bias & $\begin{array}{l}\text { Clear classification of intervention groups, prospective } \\
\text { study design. }\end{array}$ \\
\hline $\begin{array}{l}\text { Bias due to deviations from intended } \\
\text { interventions }\end{array}$ & Low risk of bias & $\begin{array}{l}\text { The study authors report "the patients were neither aware } \\
\text { of nor trained in the pain management programme and } \\
\text { they were asked exactly the same question in both } \\
\text { phases, though by different persons" }\end{array}$ \\
\hline Bias due to missing data & No information & Only $1.3 \%$ of records missing from retrospective audit. \\
\hline Bias in measurement of outcomes & Serious risk of bias & $\begin{array}{l}\text { The study authors report "The pain scores in the control } \\
\text { group were asked when patients were at rest, not } \\
\text { undergoing interventions, which may have led to } \\
\text { relatively low pain levels at that particular moment ... . } \\
\text { during the intervention phase, nurses were trained to be } \\
\text { more alert of high NRS levels compared to the control } \\
\text { phase" }\end{array}$ \\
\hline Bias in selection of the reported result & No information & Not described \\
\hline Overall quality assessment & Moderate risk of bias & \\
\hline Study authors & Whipple et al. ${ }^{55}$ & \\
\hline Bias & Judgement & Support for judgement \\
\hline Bias due to confounding & Serious risk of bias & $\begin{array}{l}\text { Potential confounding factors not addressed by } \\
\text { experimental design or statistical analyses }\end{array}$ \\
\hline Bias in selection of participants into the study & Serious risk of bias & $\begin{array}{l}\text { Retrospective review of PCA errors. No strategies to } \\
\text { minimise selection bias reported. }\end{array}$ \\
\hline Bias in classification of interventions & Low risk of bias & Clear classification of intervention groups. \\
\hline $\begin{array}{l}\text { Bias due to deviations from intended } \\
\text { interventions }\end{array}$ & Low risk of bias & Objective review of PCA errors using defined criteria. \\
\hline Bias due to missing data & Low risk of bias & No attrition of data due to the nature of the study. \\
\hline Bias in measurement of outcomes & No information & $\begin{array}{l}\text { Measures to reduce bias in outcome measurement not } \\
\text { described }\end{array}$ \\
\hline Bias in selection of the reported result & No information & Not described. \\
\hline Overall quality assessment & Moderate risk of bias & \\
\hline
\end{tabular}




\section{A.4. | Appendix}

Intervention complexity assessment.

Summary of complexity assessment of interventions primarily addressing appropriate opioid use opioids in the hospital inpatient setting $(n=31)$.

\begin{tabular}{|c|c|c|c|}
\hline Intervention type (n) & Primary author & Shania's iCAT Score* & Average iCAT Score \\
\hline \multirow{10}{*}{$\begin{array}{l}\text { Multifaceted interventions primarily aimed at } \\
\text { prescribing (16) }\end{array}$} & Taylor ${ }^{38}$ & 9.0 & \multirow[t]{10}{*}{10.4} \\
\hline & Morisson ${ }^{20}$ & 9.0 & \\
\hline & Boothby ${ }^{50}$ & 13.0 & \\
\hline & Neitzel $^{22}$ & 13.0 & \\
\hline & $\mathrm{Akce}^{52}$ & 9.0 & \\
\hline & Titsworth ${ }^{23}$ & 14.0 & \\
\hline & Benditz $^{24}$ & 14.0 & \\
\hline & Auyong ${ }^{25}$ & 10.0 & \\
\hline & Majumder $^{29}$ & 12.0 & \\
\hline & Usichenko ${ }^{30}$ & 10.0 & \\
\hline \multirow[t]{5}{*}{ Decision-making tools to guide opioid prescribing (5) } & Moustafa ${ }^{39}$ & 8.0 & \multirow[t]{5}{*}{7.4} \\
\hline & Baehren $^{40}$ & 7.0 & \\
\hline & McAllister $^{41}$ & 7.0 & \\
\hline & Netherton ${ }^{42}$ & 8.0 & \\
\hline & McEvoy ${ }^{56}$ & 7.0 & \\
\hline \multirow[t]{5}{*}{ Interventions to improve patient monitoring (10) } & Muntlin ${ }^{43}$ & 8.0 & \multirow[t]{5}{*}{7.3} \\
\hline & Chanques ${ }^{36}$ & 8.0 & \\
\hline & Paul $^{53}$ & 7.0 & \\
\hline & Ferguson $^{54}$ & 7.0 & \\
\hline & Whipple ${ }^{55}$ & 6.0 & \\
\hline
\end{tabular}

*Overall intervention complexity was calculated by assigning each criteria a score of 0 to 4 , indicating a low or high degree of complexity using the Cochrane Intervention Complexity Assessment Tool for Systematic Reviews (iCAT_SR). ${ }^{19}$ 